\title{
PRESENT-DAY SEA LEVEL CHANGE: OBSERVATIONS AND CAUSES
}

\author{
A. Cazenave \\ Laboratoire d'Etudes en Géophysique et \\ Océanographie Spatiales \\ GRGS, CNES, Toulouse, France
}

\author{
R. S. Nerem \\ Colorado Center for Astrodynamics Research \\ and Cooperative Institute for Research in \\ Environmental Sciences \\ University of Colorado, Boulder, Colorado, USA
}

Received 24 June 2003; revised 16 January 2004; accepted 24 March 2004; published 27 July 2004.

[1] The determination of the present-day rate of sea level change is important for a variety of scientific and socioeconomic reasons. With over a decade of precision sea level measurements from satellite altimetry in hand and with the recent launch of new satellite missions addressing different aspects of sea level change, observationally, we have more information on sea level change than ever before. In fact, the geocentric rate of global mean sea level rise over the last decade (1993-2003) is now known to be very accurate, $+2.8 \pm 0.4 \mathrm{~mm} / \mathrm{yr}$, as determined from TOPEX/ Poseidon and Jason altimeter measurements, $3.1 \mathrm{~mm} / \mathrm{yr}$ if the effects of postglacial rebound are removed. This rate is significantly larger than the historical rate of sea level change measured by tide gauges during the past decades (in the range of $1-2 \mathrm{~mm} / \mathrm{yr}$ ). However, the altimetric rate could still be influenced by decadal variations of sea level unrelated to long-term climate change, such as the Pacific Decadal Oscillation, and thus a longer time series is needed to rule this out. There is evidence that the sea level rise observed over the last decade is largely due to thermal expansion, as opposed to the influx of freshwater mass from the continents. However, estimates of thermal expansion are still sufficiently uncertain to exclude some contribution of other sources, such as the melting of mountain glaciers and polar ice. Moreover, independent measurements of total ice melting during the 1990 s suggest up to $0.8 \mathrm{~mm} / \mathrm{yr}$ sea level rise, an amount that could eventually be canceled by change in land water storage caused by anthropogenic activities. Another important result of satellite altimetry concerns the nonuniform geographical distribution of sea level change, with some regions exhibiting trends about 10 times the global mean. Thermal expansion appears responsible for the observed regional variability. For the past 50 years, sea level trends caused by change in ocean heat storage also show high regional variability. The latter observation has led to questions about whether the rate of 20th century sea level rise, based on poorly distributed historical tide gauges, is really representative of the true global mean. Such a possibility has been the object of an active debate, and the discussion is far from being closed. INDEX TERMS: 4556 Oceanography: Physical: Sea level variations; 1635 Global Change: Oceans (4203); KEYWORDS: sea level change.

Citation: Cazenave, A., and R. S. Nerem (2004), Present-day sea level change: Observations and causes, Rev. Geophys., 42, RG3001, doi:10.1029/2003RG000139.

\section{INTRODUCTION}

[2] Sea level change is of great interest for two fundamental reasons. First, changes in the rate of sea level rise are intimately related to changes in the Earth's climate. Second, sea level change has important socioeconomic consequences for populations living near the current mean sea level. Thus it is important to determine the current rate of global sea level change, to determine if this rate is accelerating, and to identify the causes of these changes. The latter is important for determining if the observed changes in sea level are related to anthropogenic or natural causes. More fundamentally, determining the current rate and acceleration of sea level change is important for corroborating predictions of temperature and sea level change from global climate models.

[3] Arguably, the most authoritative sources of climate predictions are from the reports of the Intergovernmental Panel on Climate Change (IPCC), which are assembled by a group of international scientists from a compendium of different climate observations and climate model predictions. The 2001 IPCC report includes a chapter dedicated to sea level change [Churchetal.,2001] that summarizes much of what we know about past, current, and future sea level change, though there have been important new developments in the field since this chapter was written. As shown in Figure 1, the best estimate of sea level change over the last century based mainly on tide gauge observations is $1.5 \pm 0.5 \mathrm{~mm} / \mathrm{yr}$, with a range of 1-2 mm/yr [Church et al., 2001]. However, independent estimates of the individual contributions to sea level change (thermal expansion, melting ice, terrestrial water storage, etc.) are much more uncertain and, when summed, suggest a total sea level change of $0.7 \pm 1.5 \mathrm{~mm} / \mathrm{yr}$. Ultimately, even if the total sea level change can be precisely determined, the cause of sea level change will not be determined until we know the relative contributions of the main components, which are still highly uncertain (Figure 1). 


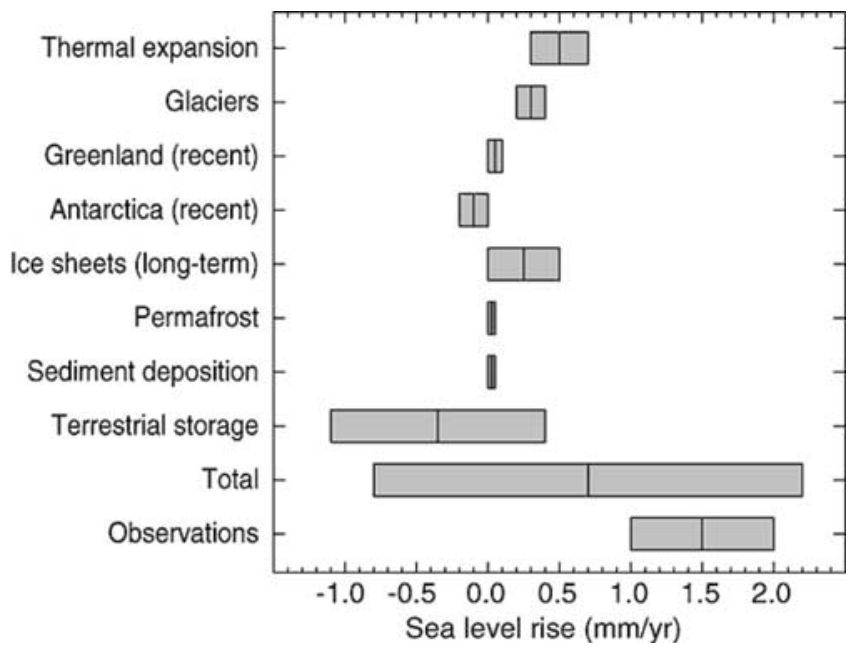

Figure 1. Estimates of the contributions to global sea level rise from Church et al. [2001]. From Intergovernmental Panel on Climate Change.

[4] Church et al. [2001] also present projections for future sea level rise based on the predictions of global climate models. As shown in Figure 2, the predictions over 1990-2100 vary between 9 and $88 \mathrm{~cm}$ (on average, between 0.8 and $8.0 \mathrm{~mm} / \mathrm{yr}$ ) with a central value of $4.4 \mathrm{~mm} / \mathrm{yr}$. As shown in Figure 2, the rate of sea level rise is expected to increase over the next century. Therefore, if future in situ or satellite observations confirm this increase in the rate of sea level rise, then this will in effect corroborate some aspects of the climate models. Thus determining the rate of sea level change over the last century (the historical rate) is critically important in order to determine if the present-day rate of sea level change has changed appreciably. As will be discussed, the present-day rate of sea level change is determined from TOPEX/Poseidon $(\mathrm{T} / \mathrm{P})$ satellite altimetry measurements over the last decade to be $+2.8 \pm 0.4 \mathrm{~mm} / \mathrm{yr}(3.1 \mathrm{~mm} / \mathrm{yr}$ after correcting for the effects of postglacial rebound); thus this could already represent a significant increase depending on what value is accepted for the historical rate.

[5] The purpose of this paper is to summarize the current knowledge of present-day sea level rise and how it relates to past and future changes in sea level. Current uncertainties and problems will be discussed. The observational results will be reviewed, followed by our current interpretation of these observations in the context of the entire Earth system. An important goal of our review is to move closer to resolving the "enigma" of sea level change (i.e., the factor 2 difference between observations and climatic contributions) over the last 50 years [Munk, 2002].

[6] In this paper, we will use the following definitions:

[7] "Steric" sea level represents sea level change due to ocean volume change that results from temperature and salinity variations. Temperature change is called "thermosteric" (or thermal expansion), while salinity change is called "halosteric."

[8] "Eustatic" sea level change represents water mass added to (or removed from) the oceans as a result of water mass exchange between the oceans and other surface reservoirs (ice sheets, glaciers, land water reservoirs, and the atmosphere).

\section{SEA LEVEL OBSERVATIONS}

[9] There are essentially two types of observations that measure sea level directly: (1) tide gauge measurements, which in a few cases go back over 100 years, and (2) satellite altimeter measurements, which are available only over 1 decade. Other measurements provide constraints on different aspects of sea level change but indirectly. For example, ocean temperature measurements in sufficient quantity and distribution can be used to infer the sea level change due to thermal expansion, and ocean salinity measurements have been used to infer the amount of freshwater entering the ocean from the continents. Being sensitive to surface mass redistribution, changes in the Earth's rotation rate, and/or gravitational oblateness $\left(J_{2}\right)$ also provide indirect constraints on ocean mass change due to meltwater mass exchange between mountain glaciers or ice sheets and the oceans. In sections 2.1 and 2.2 we review recent sea level observations from tide gauges and satellite altimetry. In situ hydrographic measurements are briefly discussed in section 4.1, while indirect observations of ocean mass variations are presented in section 6 .

\subsection{Tide Gauges}

[10] Tide gauge measurements are the principal data set used to determine the historical rate (last 50-100 years) of

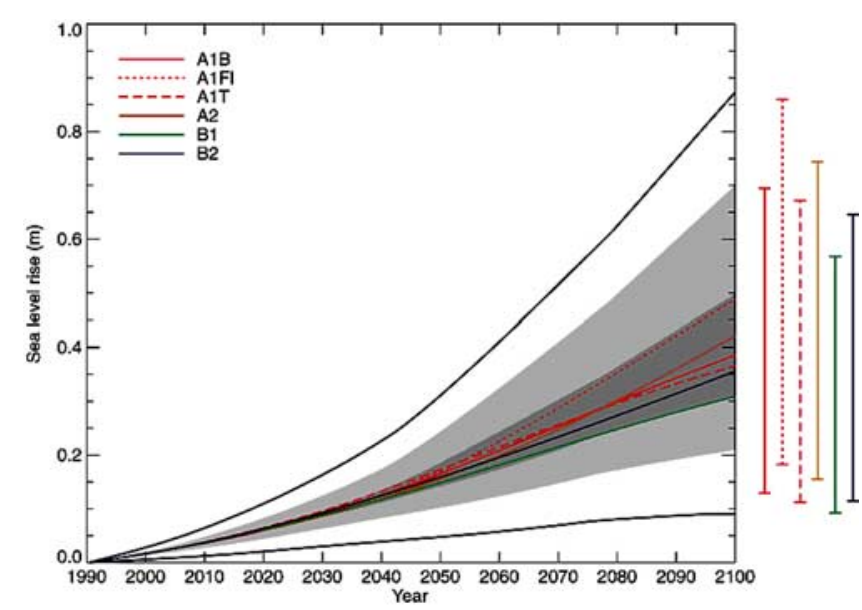

Figure 2. Predictions of global sea level rise over 19902100 from a suite of global climate models from Church et al. [2001]. Each of the colored lines is the average of different climate models for a given climate change scenario, so the lines on the right-hand side of Figure 2 represent the range of predictions given by the different models for that scenario. The dark shading shows the range of the climate model average for all scenarios, and the lighter shading shows the range for all climate models over all scenarios. The outermost lines show the range of all climate models and scenarios. These ranges do not account for uncertainties related to the West Antarctic ice sheet. From Intergovernmental Panel on Climate Change. 


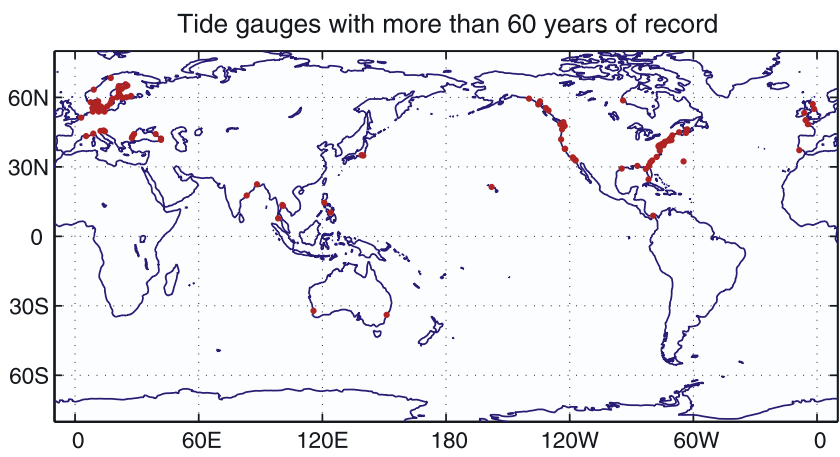

Tide gauges with more than 30 years of record

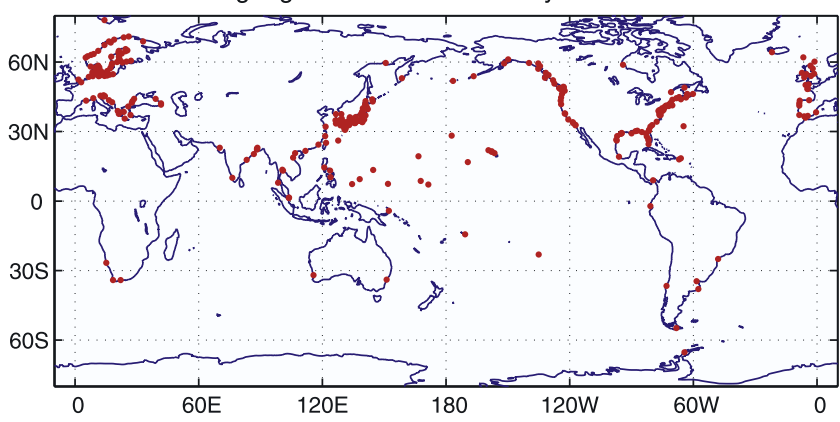

Figure 3. Distribution of data in the Permanent Service for Mean Sea Level database [Woodworth and Player, 2003] (image courtesy of G. Mitchum, 2003). Tide gauges with (top) more than 60 years of data and (bottom) more than 30 years of data.

sea level change [Douglas, 2001; Woodworth and Player, 2003]. Tide gauges provide excellent measurements of relative sea level change (relative to the Earth's crust), but determining absolute sea level change (which is the variable of interest for climate studies) from tide gauge measurements is much more problematic. Tide gauge measurements suffer from two main limitations: (1) They have poor spatial distribution, being located only on the continental margins and ocean islands (Figure 3), and (2) they are attached to the land, which can move vertically [Cazenave et al., 1999; Nerem and Mitchum, 2002], thus creating an apparent sea level change that is unrelated to climate variations. Douglas et al. [2001] and Peltier [2001] selected tide gauges away from tectonically active areas and made corrections for postglacial rebound (the vertical motion of the Earth's crust since the last deglaciation) using models [Mitrovica and Peltier, 1989; Peltier, 2001] and obtained a rate of approximately $1.8 \mathrm{~mm} / \mathrm{yr}$, which is representative of rates obtained by other authors from analysis of the tide gauge data [e.g., Douglas, 1995]. However, even under these circumstances, vertical land motion remains a significant error source for tide gauge measurements of sea level change. While geodetic leveling is used to monitor the position of the tide gauge relative to a benchmark on the land, the motion of the benchmark is often poorly known. The tide gauge selection criteria employed by Douglas [1991] reduce the number of useful records to $\sim 25$ tide gauges. Thus a possibly larger error source for historical sea level change estimates is the poor spatial sampling of the tide gauges, which could bias the global sea level rise estimates too high [Cabanes et al., 2001b]. There is some disagreement on the interpretation of this result, and further research is needed so that the tide gauge measurements can be interpreted in the proper context with satellite altimetry.

\subsection{Satellite Altimetry}

[11] The era of precision satellite altimetry began with the launch of TOPEX/Poseidon in 1992, although the road to success with T/P was paved by earlier less accurate missions such as GEOS-3, Seasat, Geosat, and ERS-1. T/P ushered in a new paradigm in satellite altimetry, largely because of advances in the instruments, the orbit determination [Tapley et al., 1994], and the instrument calibration [Christensen et al., 1994; Mitchum, 1994]. With the launch of the Jason mission in 2001 the decade-long time series of precision satellite altimetry measurements can now be seamlessly extended. Estimating global mean sea level variations from the $\mathrm{T} / \mathrm{P}$ measurements is a reasonably straightforward exercise if careful attention is paid to the measurement corrections and the instrument calibration.

[12] The altimeter measures the range between the satellite and the sea surface at two different microwave frequencies (which are combined into a single ionosphere-corrected range). The orbit height is determined via precision orbit determination techniques [Tapley et al., 1994], then an uncorrected sea level measurement is computed by subtracting the altimeter range from the orbit height. The final sea level measurement is constructed by applying corrections for atmospheric delay (dry/wet troposphere and ionosphere), sea state, atmospheric loading (inverted barometer), and solid Earth and ocean tides [Chelton et al., 2001]. For T/P (and now Jason) the point-to-point accuracy of these measurements has been shown to be $2-3 \mathrm{~cm}$ [Chelton et al., 2001]. T/P makes these measurements along a ground track that repeats once every 10 days (Figure 4). Global mean sea level can be computed at 10-day intervals by simply averaging the measurements over the ocean while accounting for the spatial distribution of the data using equi-area weighting [Nerem and Mitchum, 2001b].

[13] Numerous papers have been published on the scientific results [Cazenave et al., 1998; Minster et al., 1995; Nerem, 1995a, 1995b; Nerem et al., 1997, 1999; Leuliette et al., 2004], which currently show a rate of sea level rise of $+2.8 \pm 0.4 \mathrm{~mm} / \mathrm{yr}$ [Nerem and Mitchum, 2001a, 2001b] (Figure 5), much of which has been suggested to be steric in origin [Cabanes et al., 2001b]. A significant fraction of this change has also been shown to arise from changes in the Southern Ocean [Cabanes et al., 2001a]. The observations also show a $15-\mathrm{mm}$ rise and fall of mean sea level that accompanied the 1997-1998 El Niño-Southern Oscillation (ENSO) event [Nerem et al., 1999; White et al., 2001].

[14] The accuracy needed to compute mean sea level pushes the altimeter measurement system to its performance limits, and thus great care must taken to ensure that the instrument is precisely calibrated [e.g., Christensen et al., 1994; Haines and Bar-Sever, 1998; Hayne et al., 1994]. The 


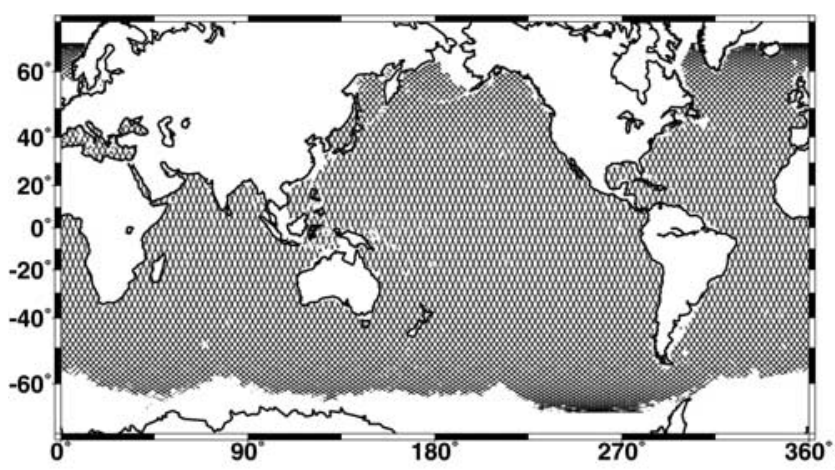

Figure 4. Distribution of altimeter data for a typical TOPEX/Poseidon (T/P) 10-day repeat cycle. The gaps in the Southern Ocean are due to sea ice.

calibration activities generally have three different objectives: (1) determining the absolute bias in the instrument for the purpose of computing absolute sea level; (2) determining changes in the bias versus time for the purpose of computing changes in sea level; and (3) determining the relative bias between two different instruments (e.g., T/P and Jason) for the purposes of assembling an uninterrupted record of sea level change from multiple instruments. For the latter two objectives it has been demonstrated that comparing the altimeter sea level measurements to tide gauge sea level measurements produces the most robust results [Chambers et al., 1998; Mitchum, 1994, 1997, 1998, 2000]. Figure 6 shows a time series of the altimeter instrument behavior derived by Mitchum [2000] using these techniques. The abrupt change at the end of 1998 was due to switching to the redundant altimeter electronics on the satellite (side A to side B), so effectively T/P has used two separate instruments during its mission, each of which should be expected to have different behavior. Errors in

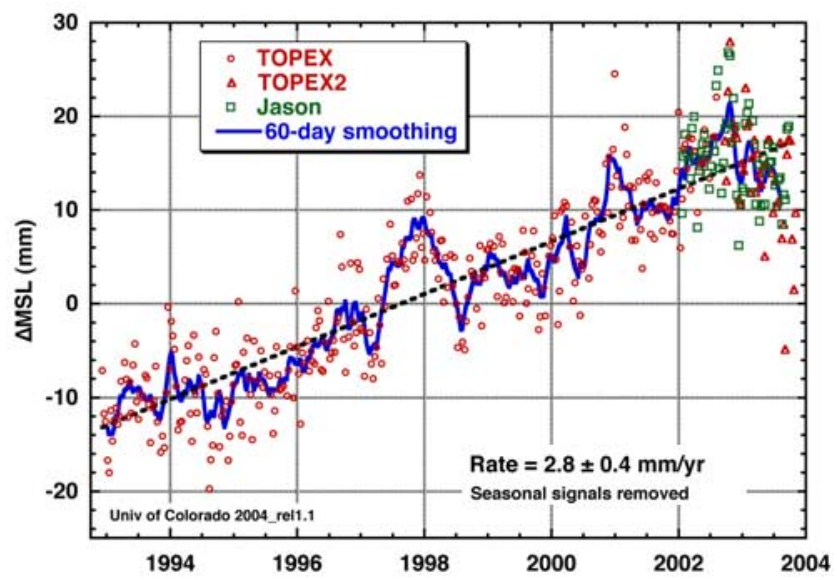

Figure 5. Global mean sea level variations every 10 days from $\mathrm{T} / \mathrm{P}$ (red circles, red triangles after $\mathrm{T} / \mathrm{P}$ was moved to new ground track) and Jason (green squares) and after smoothing with a 60-day boxcar filter (blue line) [Leuliette et al., 2004]. No inverted barometer correction was applied to the altimeter data, and seasonal variations have been removed.

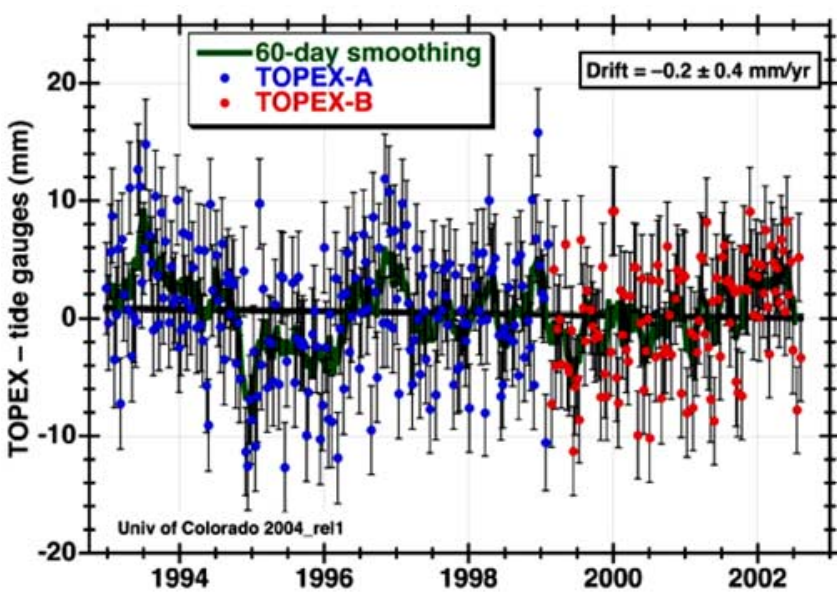

Figure 6. T/P tide gauge calibration values from Mitchum [2000] used to diagnose changes in the altimeter calibration. These values represent 10-day global averages of T/P minus tide gauge sea level differences using $\mathrm{T} / \mathrm{P}$ data in the vicinity of 64 different tide gauges.

determining the altimeter instrument drift using the tide gauges, currently estimated to be about $0.4 \mathrm{~mm} / \mathrm{yr}$, are almost entirely driven by errors in knowledge of vertical land motion at the gauges [Mitchum, 2000]. Future monitoring of the tide gauges using geodetic techniques such as GPS and Dopler orbitography and radiopositioning integrated by satellite (DORIS) will be critical if the error in the instrument calibration is to be reduced.

[15] The tide gauge calibration time series (Figure 6) is used to diagnose problems in the altimeter instrument, the orbits, the measurement corrections, and, ultimately, the final Geophysical Data Records (GDRs). Numerous improvements to the GDRs have been developed in this way and used to produce improved measurements (corrections to the official Geophysical Data Records (GDRs)), which are then recalibrated using the tide gauges. Figure 6 can be regarded as an estimate of the error in the mean sea level time series shown in Figure 5. While in the past we have used the tide gauge calibration values as direct corrections to the altimeter data, recent improvements in the sea state bias correction [Chambers et al., 2003] now make this unnecessary, as the curve is relatively flat. In summary, the altimetric results are considered to be extremely robust, and the estimate of sea level rise of $2.8 \pm 0.4 \mathrm{~mm} / \mathrm{yr}$ over the last decade is very reliable within these error bars.

[16] An important result of T/P altimetry is mapping of the geographical distribution of sea level change (Figure 7). While in tide gauge-derived sea level studies most investigators assumed uniform sea level change, now we have, for the first time, unambiguous evidence of regional variability of sea level change, some regions exhibiting sea level trends about 10 times the global mean. It is in the western Pacific and eastern Indian Oceans that sea level rise presents the highest magnitude. It is also worth noting that the whole Atlantic Ocean shows sea level rise during the past decade. In contrast, Figure 7 shows that sea level has been dropping in some regions (eastern Pacific and western 

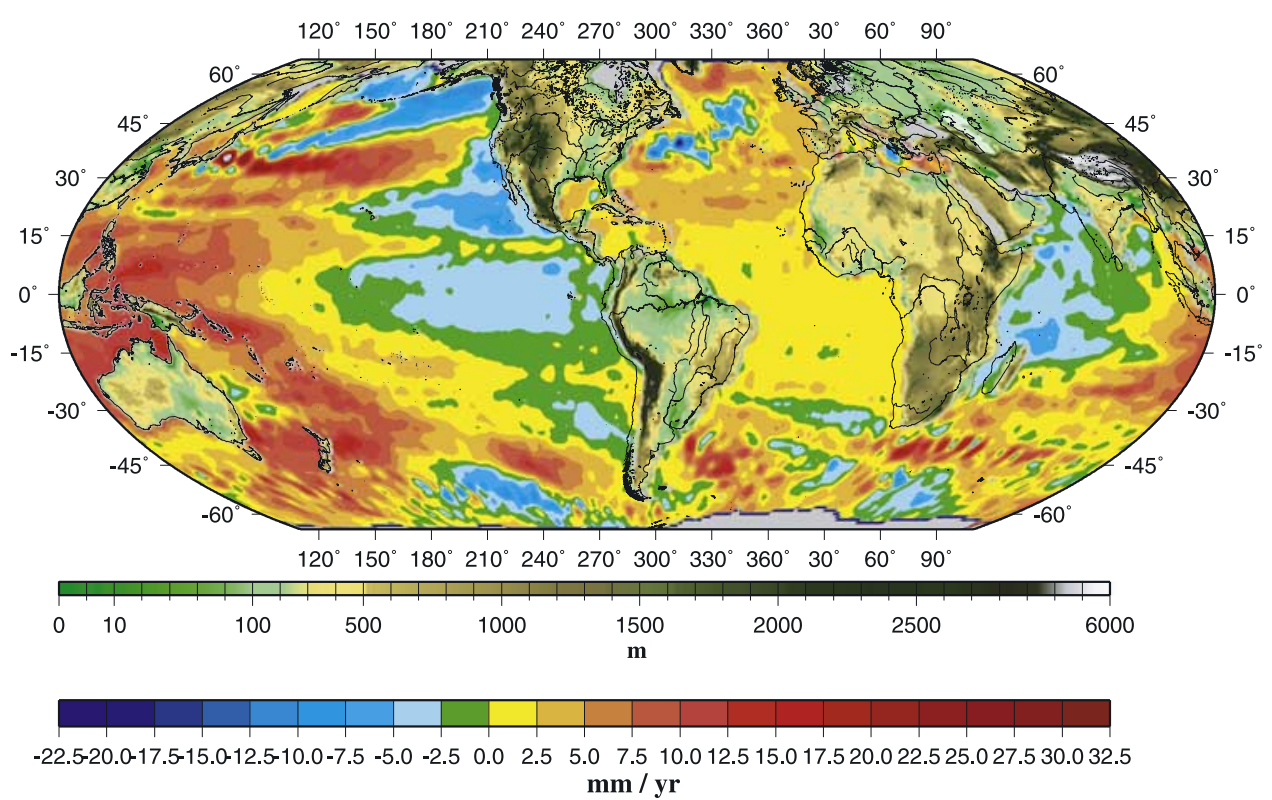

Figure 7. Sea level trends over 1993-2003 from the T/P mission. The global average of this map gives the $2.8 \mathrm{~mm} / \mathrm{yr}$ value shown in Figure 5. The pattern of sea level change is largely due to the impact of decadal-scale variability on the relatively short altimeter time series.

Indian Oceans), even though in terms of global mean, sea level has been rising.

[17] The record of sea level change from satellite altimetry is now sufficiently long that one may ask if the measured rate of sea level rise is representative of the long-term rate expected because of climate change. In order to answer this question one must know the magnitude of the interannual, decadal, and interdecadal variability of global mean sea level. Tide gauge measurements cannot provide this, as the variability observed in global mean sea level determined from tide gauges is likely driven as much by the spatial sampling as by the real global mean signals. Climate models are also suspect, since they may underestimate the true variability in the Earth system. Nerem et al. [1999] attempted to assess the variability in global mean sea level by regressing T/P sea level measurements against the Southern Oscillation Index (SOI) and sea surface temperature (SST) measurements and then using the regression coefficients to construct simulated time series of global mean sea level from the much longer SOI and SST time series. They found that roughly 1 decade of satellite altimetry should be sufficient to average out the natural variability in global mean sea level and obtain the longterm rate, and approximately 3 decades of measurements will be required to measure an acceleration in the trend. However, SOI and global mean SST may not be good proxies for sea level variability, especially for decadal variations such as the Pacific Decadal Oscillation (PDO). Recently, similar conclusions were drawn using a reconstruction of global mean sea level employing tide gauge data and T/P altimeter data [Chambers et al., 2002]. If these assessments are correct, then tide gauge data will continue to be important for at least several more decades as a baseline for measuring climate change using satellite altimetry, since altimetry alone cannot currently detect a change in the rate.

\section{SEA LEVEL RISE DURING THE 20TH CENTURY: IPCC THIRD ASSESSMENT REPORT}

[18] The chapter on sea level change of the IPCC report [Church et al., 2001] reevaluates climate-related contributions to the 20th century sea level rise (Figure 1). The largest positive contribution $(0.3-0.7 \mathrm{~mm} / \mathrm{yr}$ of sea level rise) arises from thermal expansion due to warming of the oceans that mainly occurred since the 1950s. This estimate is based on ocean general circulation models (OGCMs). Melting of mountain glaciers produces $0.2-0.4 \mathrm{~mm} / \mathrm{yr}$ sea level rise. Estimated Greenland and Antarctica mass imbalance (accounting for a long-term readjustment since the Last Glacial Maximum plus a climate-related response) contributes -0.2 to $0.6 \mathrm{~mm} / \mathrm{yr}$. The most uncertain contribution is the change in terrestrial water storage that results from human activities, which is in the range of -1.1 to $+0.4 \mathrm{~mm} / \mathrm{yr}$ with a median value of $-0.35 \mathrm{~mm} / \mathrm{yr}$ (i.e., corresponding to sea level drop). The sum of these contributions ranges from -0.8 to $2.2 \mathrm{~mm} / \mathrm{yr}$, with a median value of $0.7 \mathrm{~mm} / \mathrm{yr}$. As we have seen, values for the 20th century sea level rise based on tide gauge records are in the range of 1-2 mm/yr. The most recent determinations are $1.76 \pm$ $0.55 \mathrm{~mm} / \mathrm{yr}$ [Douglas, 2001] and $1.84 \pm 0.35 \mathrm{~mm} / \mathrm{yr}$ after correcting for postglacial rebound [Peltier, 2001]. Church et al. [2001] adopt as a best estimate a value of $1.5 \pm$ $0.5 \mathrm{~mm} / \mathrm{yr}$ and note that the sum of climate-related components is low $(0.7 \mathrm{~mm} / \mathrm{yr})$ compared to observations. In effect, the observed value is more than twice as large as the revised estimate of the total climate contributions, although there is complete overlap between their respective 


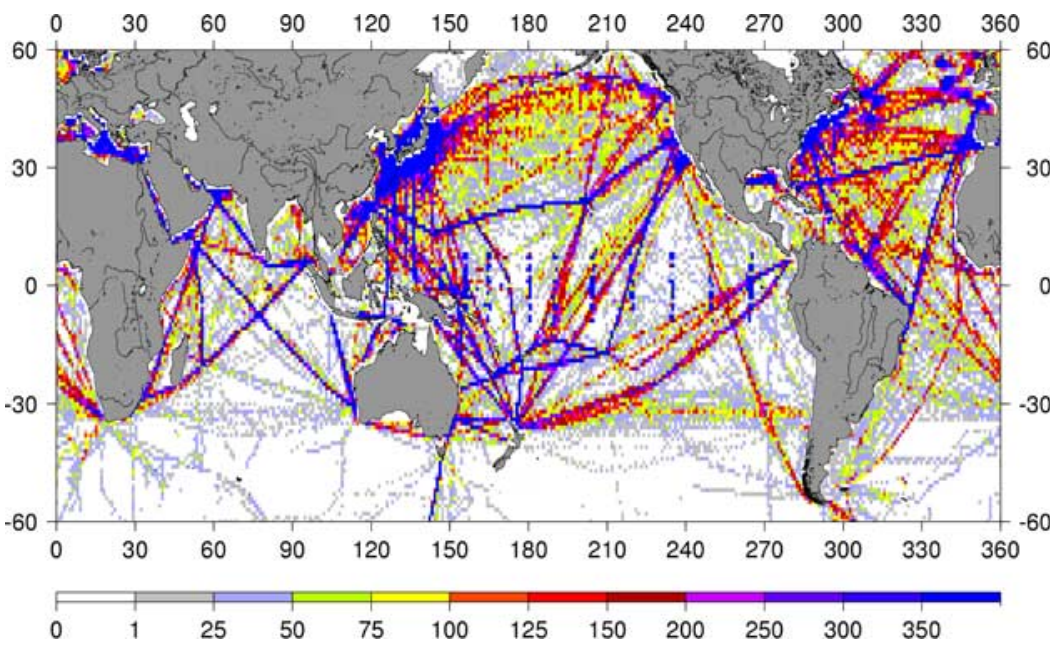

Figure 8. Distribution of hydrographic measurements (depth range 0-3000 m) over 1980-1990 from Levitus et al. [2000b]. The color scale refers to the number of available profiles over the 10-year time span.

uncertainties. It thus appears that either the climate-related processes causing sea level rise have been underestimated or the rate of sea level rise observed with tide gauges is in error. Munk [2002] refers to this as "The Enigma."

[19] To explain the difference between the climate-related contributions and the observed 20th century sea level rise, several hypotheses may be invoked.

[20] 1. Estimates of thermal expansion based on OGCMs are underestimated.

[21] 2. Tide gauge-based sea level rise is overestimated. The latter possibility could result from the regional variability of the rate of sea level change, inadequately sampled by the few tide gauges available for the historical period.

[22] 3. Eustatic contributions are larger than estimated by Church et al. [2001].

[23] 4. Missing contributions not estimated by Church et al. [2001] (e.g., salinity effects and land water mass contribution due to change in the global water cycle) could eventually reduce the discrepancy with the observations.

[24] In sections 4-7 we successively examine each of the above possibilities. To begin with, let us discuss thermal expansion over the past decades.

\section{WARMING OF THE OCEANS DURING THE PAST 50 YEARS}

\subsection{Global Temperature and Salinity Data Sets}

[25] Despite the advances that have been made in satellite oceanography, hydrographic measurements from oceanographic vessels and subsurface buoys remain one of the only tools for probing the subsurface of the ocean. While satellite altimetry measures the total sea level as expressed in the surface topography of the ocean, currently only hydrographic measurements can determine the steric component of this change. Over the previous decades, hydrographic measurements, in particular temperature and salinity, have been collected by buoys, commercial ships, and oceanographic cruises. However, these data suffer considerable gaps both in time and space: The farther back in time and the deeper below the surface, the scarcer the data are. The remote Southern Ocean is poorly covered at all depths whatever the time span. The situation improved significantly during the 1990s with the World Ocean Circulation Experiment (WOCE) project, an international initiative to develop surface and subsurface observing systems together with satellite-derived SST and sea surface height observations, with the objective of studying ocean dynamics at a global scale. Moreover, in the context of the international ARGO program (see www.argo.ucsd.edu) a global network of several thousand profiling floats is currently being deployed for measuring temperature and salinity. However, for the recent decades the spatial distribution of temperature observations is limited, especially in the Southern Ocean. This is illustrated in Figure 8 showing temperature profiles coverage for 1980-1990. For salinity, coverage is even worse; thus caution must be used in interpreting any interpolated result derived from the raw measurements.

[26] Subsurface temperature data are stored in various formats with respect to different vertical levels. In addition, from one measurement date to another, site locations often vary. Thus, for easier handling of these observations, data interpolation at standard ocean depths and geographical positions is usually performed. Recently, Levitus et al. [2000b] and Ishii et al. [2003] provided global gridded temperature data sets for 1950-1998 based on objective analysis methods applied to the raw data. The Levitus et al. [2000a] data set consists of $1^{\circ} \times 1^{\circ}$ gridded temperature fields given as yearly means for the upper $500 \mathrm{~m}$ for 1945 1998 and as 5-year means for depths down to $3000 \mathrm{~m}$ for 1945-1996. The Ishii et al. [2003] data set is derived from an objective analysis based on a computational scheme different from Levitus et al. [2000b] but using similar raw temperature data for 1950-1990 (the National Oceanic and Atmospheric Administration/National Oceanographic Data Center). For years 1991-1998, Ishii et al. [2003] used different data: a data set archived by the Pacific Marine Environmental Laboratory for the tropical Pacific Ocean 
and a data set from the Japanese Meteorological Agency for the global ocean completed by data in the seas around Japan; in addition, SST data from various sources are also used. The Ishii et al. [2003] data set consists of monthly gridded temperatures and associated uncertainties down to $500 \mathrm{~m}$ for $1950-1998$.

\subsection{Steric Contribution to Sea Level Rise Observed During the 1990s}

[27] In this section we examine the steric contribution to sea level rise during the $\mathrm{T} / \mathrm{P}$ mission. Using the global ocean temperature data set described in section 4.1 , it is now possible to estimate the thermosteric contribution to sea level rise, in particular for the recent years. To compute the thermosteric sea level, gridded temperature anomalies need first to be converted in terms of density anomalies at each standard level using the classical expression for the equation of state of the ocean [Gill, 1982]. The thermosteric sea level is further obtained by vertically integrating density anomalies at each grid point and each time step according to

$$
h_{\text {steric }}(x, y, t)=\int_{-H}^{0} \frac{\rho_{0}(x, y, z)-\rho(x, y, z, t)}{\rho_{0}(x, y, z)} d z,
$$

where $H$ is reference depth, $\rho_{0}(x, y, z)$ is the reference density and $\rho_{0}$ is a function of the reference temperature $T_{0}$, reference salinity $S_{0}$, and depth $z ; \rho(x, y, z, t)$ is a nonlinear function of temperature and salinity [e.g., Gill, 1982].

[28] Cabanes et al. [2001b] used the Levitus et al. [2000b] temperature data set over the 6-year interval (1993-1998) overlapping with $\mathrm{T} / \mathrm{P}$ and compared sea level trend maps for T/P-derived and thermosteric sea level for the time span 1993-1998. They found that observed and steric sea level trends agree very well [see Cabanes et al., 2001b, Figure 2]. Over the 6-year (19931998) overlapping time span between the two data sets the thermosteric sea level rise amounts to $3.1 \pm 0.4 \mathrm{~mm} / \mathrm{yr}$, while T/P measures a rate of $3.2 \pm 0.2 \mathrm{~mm} / \mathrm{yr}$. They concluded that thermal expansion is the main contribution to the observed sea level change during the past decade. Figure 9 compares T/P-based sea level trends with thermal expansion trends based on the Ishii et al. [2003] data set for 1993-1998. As for the Levitus data, the agreement between the two maps is striking, in particular in the tropics and the Northern Hemisphere. In the Southern Ocean (south of $30^{\circ} \mathrm{S}$ ), however, the T/P-based positive sea level trends are poorly reproduced by the thermosteric trend map. This could result from the lack of temperature data in these remote regions. Using temperature data recorded by floats between $700 \mathrm{~m}$ and $1000 \mathrm{~m}$, Gille [2002] reports important warming of the Southern Ocean since the 1950s. Although the latter in situ temperature data set concerns a limited depth range, it suggests that the Southern Ocean has warmed during the past decades, in particular the 1990s. Thus we cannot exclude that the positive sea level trends seen by $\mathrm{T} / \mathrm{P}$ in the austral ocean are of thermal origin.
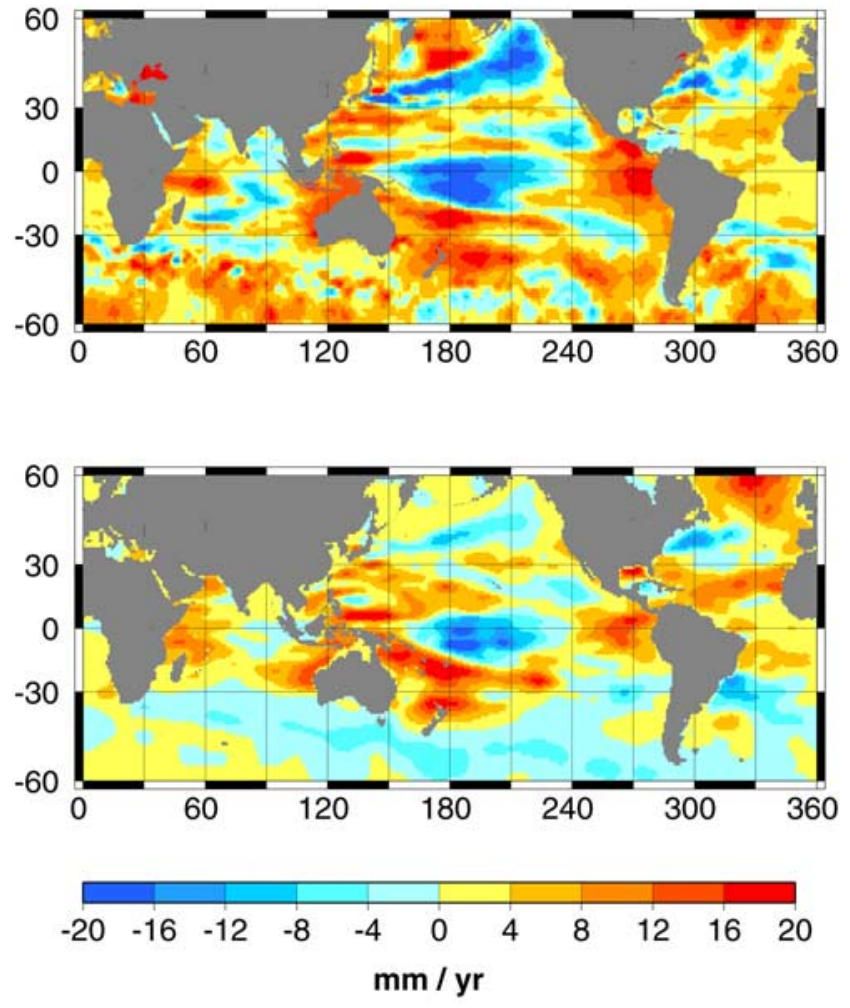

Figure 9. Comparison of sea level trend maps of (top) total sea level derived from T/P and (bottom) thermosteric sea level based on the Ishii et al. [2003] data for the time span 1993-1998. Units are in mm/yr. From Lombard et al. (submitted manuscript, 2004).

[29] The correlation between $\mathrm{T} / \mathrm{P}$ and thermosteric (Ishii based) sea level trends for the $60^{\circ} \mathrm{N}-30^{\circ} \mathrm{S}$ region is 0.71 . This correlation is only 0.6 when the Levitus data are used. Processing errors affecting the latter temperature data set beyond 1990 (S. Levitus, personal communication, 2003) may explain the smaller correlation. Comparing Figure 2 from Cabanes et al. [2001b] and Figure 9 indicates that the Levitus-based map contains more high-frequency signal than the Ishii-based map. This high-frequency signal may not be real and may possibly be a result of the interpolation process.

[30] In a recent study, Guinehut [2002] analyzed in situ temperature and salinity data from various sources (expendable bathythermograph (XBT) data from the WOCE and Tropical Ocean-Global Atmosphere programs, conductivity-temperature-depth data from WOCE, and data from profiler floats, etc.) over the period 1993-1999. Because of the sparse distribution of the data at depth, in particular the XBT data, which represent $92 \%$ of the entire data set, the derived steric (both thermosteric and halosteric) sea level is representative of the $0-$ to $700-\mathrm{m}$ water column. Unlike Levitus et al. [2000b] and Ishii et al. [2003], Guinehut [2002] did not construct a gridded data set from original profiles. Rather she interpolated on a monthly basis, $1^{\circ} \times 1^{\circ}$ gridded sea level data based on T/P plus ERS-1 and ERS-2 altimetry, at the location of the in situ temperature measurements. Over 1993-1999 
the mean sea level trend averaged at the in situ data points amounts to $3.2 \pm 0.5 \mathrm{~mm} / \mathrm{yr}$ for the altimetry data and $3.5 \pm 0.3 \mathrm{~mm} / \mathrm{yr}$ for the steric data. Using the same in situ hydrographic data set, A. Lombard et al. (Contribution of thermal expansion to present-day sea level change revisited, submitted to Global Planet Change, 2004, hereinafter referred to as Lombard et al., submitted manuscript, 2004) extended Guinehut's method to the period 1993-2001 and found similar rates $(2.5 \mathrm{~mm} / \mathrm{yr})$ for altimetry-derived and steric sea level rise. Using in situ temperature data over 1993-2002, Chambers [2003] also found a high steric rate of rise $(3.7 \pm 1.5 \mathrm{~mm} / \mathrm{yr})$. These new investigations appear to confirm the Cabanes et al. [2001b] result; that is, for the past few years the steric contribution is the dominant contributor to the observed sea level rise.

[31] The good agreement between altimetry-based sea level rise during the 1990s and thermal expansion does not imply that eustatic contributions are negligible. In section 5 we present recent results on the sea level contribution from the melting of mountain glaciers and the polar ice sheets. We will see that these contributions to sea level rise are, in fact, quite significant. This could mean that a negative contribution counterbalances the positive eustatic component (this will be discussed in section 5) or that the steric contribution has been overestimated. Such a possibility cannot be excluded considering the lack of temperature data in the remote Southern Ocean. Besides, very recent results by Willis et al. [2003], based on in situ hydrographic measurements with different coverage than given by Lombard et al. (submitted manuscript, 2004) and Chambers [2003], suggest a steric contribution of $1.8 \pm 0.3 \mathrm{~mm} / \mathrm{yr}$ for $1993-2002$. We see that the question is still open.

\subsection{Steric Sea Level Rise for the Past 50 Years}

[32] Using the global gridded data prepared by Levitus et al. [2000b], Levitus et al. [2000a] showed that the world ocean has exhibited a net warming of $0.06^{\circ} \mathrm{C}$ during the past 50 years. In the Pacific Ocean, warming significantly increased in the early 1970s and in the mid-1980s. The Indian Ocean has also warmed significantly since the 1960s. The Atlantic Ocean shows a somewhat different behavior, with a rather monotonic positive warming trend since 1950 until the early 1990s and then a steep warming increase thereafter (probably overestimated in the 1990s (S. Levitus, personal communication, 2003)). In addition, only the Atlantic Ocean shows substantial warming at depths below $1000 \mathrm{~m}$, unlike the Pacific and Indian Oceans where change in heat content mainly occurs in the upper $300 \mathrm{~m}$. Antonov et al. [2002] computed the steric sea level for the period 1957-1994, using the 5-year mean temperature data set of Levitus et al. [2000b] over the depth range $0-3000 \mathrm{~m}$ and the $65^{\circ} \mathrm{N}-50^{\circ} \mathrm{S}$ domain (Figure 10). This steric sea level curve accounts for both temperature and salinity. The rate of steric sea level rise for this period amounts to $0.55 \pm$ $0.07 \mathrm{~mm} / \mathrm{yr}$, halosteric change accounting for only $0.05 \mathrm{~mm} / \mathrm{yr}$, i.e., $10 \%$ of the thermal effect. Such a steric contribution based on in situ observations is in good

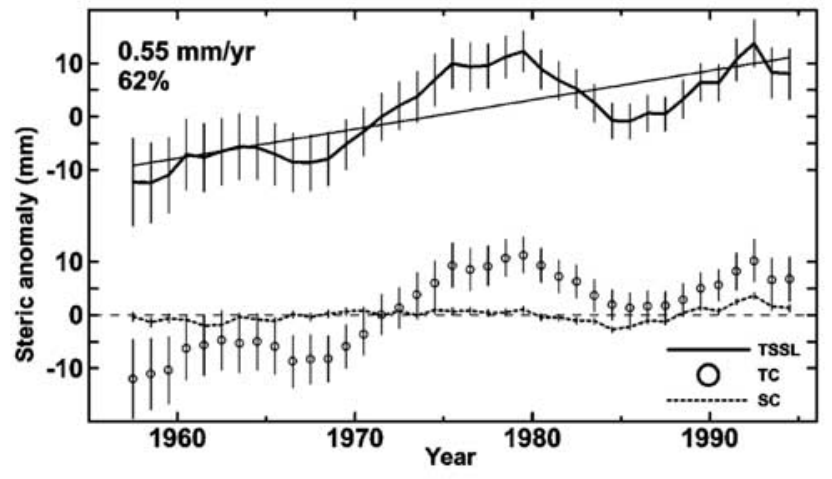

Figure 10. Time series of spatially averaged $\left(50^{\circ} \mathrm{S}-65^{\circ} \mathrm{N}\right)$ 5 -year running composites of thermosteric (TC) (circles), halosteric (SC) (dotted line), and total steric (TSSL) (solid line) anomalies (in $\mathrm{mm}$ ) of the 0 - to 3000-m layer for the 1957-1994 period. Vertical lines represent \pm 1 standard error of the 5-year mean estimates of steric components. The linear trend is plotted for the TSSL anomaly time series. The trend and the percent variance accounted for by this trend are given in the top left corner. From Antonov et al. [2002].

agreement with the Church et al. [2001] estimate for the past century, based on climate models $(0.3-0.7 \mathrm{~mm} / \mathrm{yr})$.

[33] The steric sea level curve shown in Figure 10 is characterized by strong decadal variability, with two periods of steep increase: the early 1970s and mid-1980s. Climate models appear unable to reproduce this decadal variability [Gregory et al., 2001; Sun and Hansen, 2003]. For the time being, it is unclear whether this reveals model deficiency or if these oscillations are artifacts caused by the interpolation process (as suggested by J. M. Gregory et al. (Simulated and observed decadal variability in ocean heat content, submitted to Geophysical Research Letters, 2004)).

[34] Figure 11 compares the geographical distribution of steric sea level trends for 1950-1990 computed with the Levitus et al. [2000b] and Ishii et al. [2003] data sets. As for the shorter period (1993-1998), both maps compare well, the Ishii et al. [2003] map showing smoother features. Over this 40-year period, steric sea level change is far from being spatially uniform. Several features are noticeable in the two maps shown in Figure 11: (1) the west-east dipole in the tropical Pacific associated with ENSO and PDO and (2) the north-south dipole in the North Atlantic associated with the North Atlantic Oscillation, with positive trends in the Gulf Stream region and negative trends in the subpolar gyre. In addition to these features, important regional variability is also observed in many other oceanic regions (e.g., the Indian Ocean, the North Pacific, and the austral ocean). These regional steric trend variations, either positive or negative, appear larger than $5 \mathrm{~mm} / \mathrm{yr}$ (absolute value), i.e., more than 10 times the global mean. It remains to be proven if these patterns are real or if they represent some limitation of the data set. However, in view of the very good agreement between T/P-based and steric regional trends reported for the recent years, it would not be surprising that on a longer time span, steric sea level change is also nonuniform. The origin of this spatial variability is not yet 

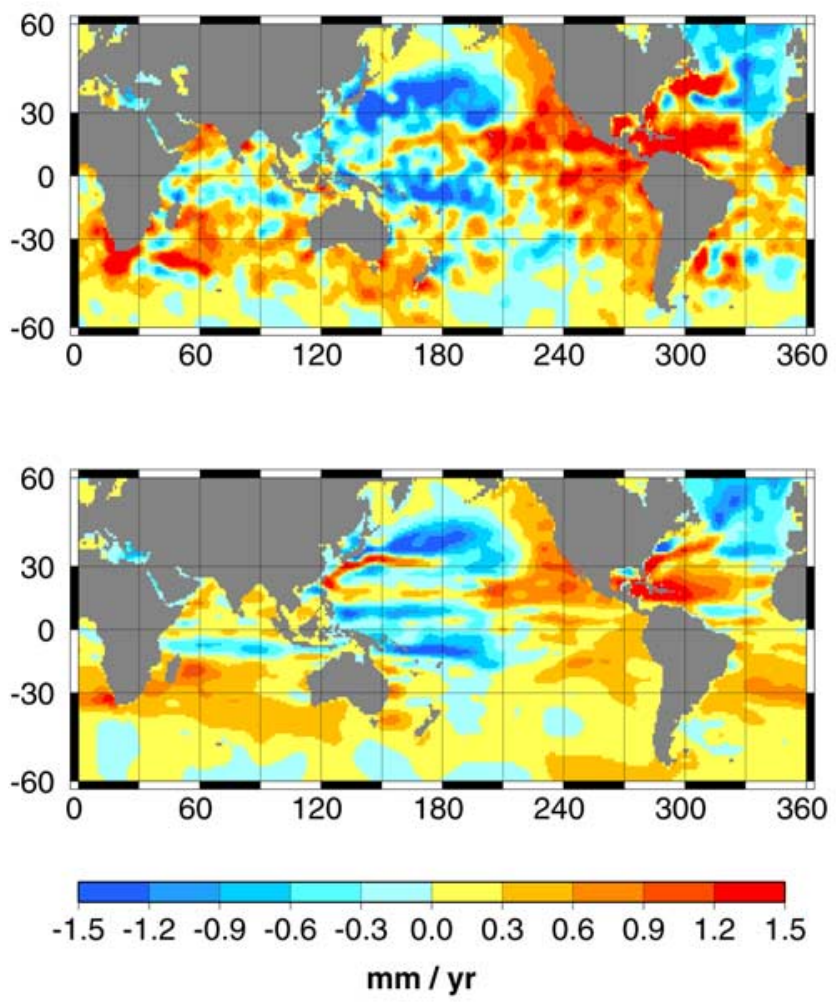

Figure 11. Thermosteric sea level trend maps for 19501990, based on temperature data from (top) Levitus et al. [2000b] and (bottom) Ishii et al. [2003]. Units are in mm/yr. From Lombard et al. (submitted manuscript, 2004).

understood but may be linked to the ocean dynamics processes, in particular to the redistribution of heat horizontally and vertically through air-sea exchange and thermohaline circulation.

[35] Cabanes et al. [2001b] noticed that the limited coverage of historical tide gauges classically used to estimate the 20th century sea level would hardly capture the spatial variability of thermosteric sea level change. These authors suggested that averaging geographically poorly distributed tide gauge data may produce biased estimates of the global average sea level change. To evaluate this, Cabanes et al. [2001b] computed a pseudo "global mean" steric sea level time series by subsampling the global thermosteric sea level grid (using the Levitus data down to $3000 \mathrm{~m}$ over 1955-1995) at locations close to tide gauge sites, considering 25 out of the 27 stations selected by Douglas [2001]. At each of the 25 sites they constructed a thermosteric sea level time series by averaging the closest $2^{\circ} \times 2^{\circ}$ gridded values. The rate of sea level rise deduced from the pseudo "global mean" thermosteric sea level time series amounts to $1.3 \pm 0.10 \mathrm{~mm} / \mathrm{yr}$, a value more than 2 times larger than the "true" global mean trend (of $0.5 \pm 0.2 \mathrm{~mm} / \mathrm{yr}$ for the thermosteric component). Hence the thermosteric component averaged at these sites exceeds the global average. Cabanes et al. [2001b] interpreted this result by the fact that most of the 25 sites are located in regions that experienced significant warming during the past 40 years, and unless the thermal component is counter- balanced by negative contributions (e.g., salinity increase), they concluded that the observed sea level rise at these tide gauge sites is possibly overestimated. To test this, they computed the observed sea level over the same 40-year time span, using tide gauge data from the Permanent Service for Mean Sea Level (PSMSL) [Woodworth and Player, 2003] and found a rate of rise of $1.6 \pm 0.2 \mathrm{~mm} / \mathrm{yr}$, just slightly larger than the pseudo "global mean" thermosteric rise $(1.3 \pm 0.10 \mathrm{~mm} / \mathrm{yr})$. The difference may result either from local salinity effects or from local eustatic contributions. To assess the role of salinity, Cabanes [2003] computed the halosteric contribution at each of the 25 stations and found significant improvement of the correlation between observed and steric sea level at individual sites. Finally, Cabanes [2003] showed that using the 287 sites of the Global Sea Level Observing System [Intergovernmental Oceanographic Commission, 1997] implemented during the 1990s provides sufficient spatial sampling that aliasing problems are minor.

[36] The Cabanes et al. [2001b] conclusion about a possible bias affecting determinations of past century global mean sea level rise with an uneven and limited distribution of the tide gauges has been the object of controversy. Miller and Douglas [2004] recently analyzed the raw hydrographic measurements used by Levitus et al. [2000b] to construct his database and concluded his interpolation scheme may have had a deleterious influence on the Cabanes et al. results. Furthermore, Miller and Douglas [2004] find a large difference between the tide gauge-determined sea level rise and the regionally averaged steric sea level rise. They suggest that it is due to a large mass contribution. As we will see in section 5, there is recent evidence for a significant eustatic contribution, at least in terms of the global mean. Clearly, both conclusions of Miller and Douglas are quite admissible. However, more work is still needed on that topic, especially because Miller and Douglas assume that the steric sea level change is geographically uniform (their hydrographic data are averaged over regions thousands of kilometers wide), an assumption that is not consistent with the Levitus et al. [2000b] and Ishii et al. [2003] thermosteric sea level trend maps.

\subsection{Contribution of Salinity}

[37] Antonov et al. [2002] showed that global mean halosteric change contributes $0.05 \mathrm{~mm} / \mathrm{yr}$ to sea level rise for the past 50 years, an order of magnitude lower than thermal expansion. On the other hand, these authors showed that, on regional scales, the halosteric contribution can be quite significant, for example, in subpolar areas of the North Atlantic, especially in the Labrador Sea where it nearly counteracts the thermosteric contribution. The positive halosteric contribution to global mean sea level change corresponds to a global salinity decrease (evaporation decrease, precipitation increase over oceanic areas, or freshwater increase from river runoff into the oceans, the exact proportion of each factor being poorly known). Antonov et al. [2002] converted the volume mean salinity change into an equivalent amount of freshwater added to the world 
ocean. They found that the freshening was equivalent to a mean sea level rise of $1.35 \pm 0.5 \mathrm{~mm} / \mathrm{yr}$. Recently, Munk [2003] used the Antonov et al. [2002] mean salinity change to reestimate the freshwater mass added to the oceans, applying a different method of calculation and accounting for floating sea ice. While sea ice melting does not raise sea level, it contributes to decreasing salinity. Several studies have reported a net decline of Northern Hemisphere sea ice volume in the recent decades [Rothrock et al., 1999; Serreze et al., 2000]. However, the exact amount of sea ice melting is still poorly known. Munk [2003] used two extreme values, corresponding to $135 \mathrm{~km}^{3} / \mathrm{yr}$ and $700 \mathrm{~km}^{3} / \mathrm{yr}$ in terms of freshwater equivalent. The former case leads to $1.4 \mathrm{~mm} / \mathrm{yr}$ eustatic sea level rise based on the salinity change over the past 50 years, while the latter would leave no room for any steric contribution. Probably the exact volume of sea ice melt lies between these two extremes (F. Joos, personal communication, 2003). To correctly interpret salinity change in terms of freshwater input to the oceans, more information is needed on sea ice melting. Moreover, estimates of past salinity change must be used with caution because coverage of salinity measurements is very scarce, with very few data in the Southern Hemisphere and in the Pacific Ocean, except along coastlines.

\section{SEA LEVEL CONTRIBUTIONS FROM CONTINENTAL WATER MASS}

[38] Variations in the amount of water stored in artificial reservoirs, soils, snowpack, aquifers, mountain glaciers, polar ice sheets, etc. can cause significant changes in global mean sea level. We will now review these different sources.

\subsection{Anthropogenic Contributions}

[39] The continental water contribution to 20th century sea level change quoted by Church et al. [2001] is that associated with human activities (Figure 1). It is in the range of -1.1 to $+0.4 \mathrm{~mm} / \mathrm{yr}$ with a central value of $-0.35 \mathrm{~mm} / \mathrm{yr}$ (i.e., corresponding to a sea level drop) [Chao, 1991; Gornitz, 2001; Gornitz et al., 1997; Sahagian, 2000].

[40] In recent studies, Gornitz [2001] and Gornitz et al. [1997] revisited the main anthropogenic processes that may alter land water storage. In decreasing order of importance these are dam and reservoir building, irrigation, urbanization, groundwater mining, deforestation, and combustion of fossil fuels. According to Gornitz [2001], anthropogenic effects on the land hydrologic cycle affect sea level change as follows:

$$
\mathrm{SLC}=(G+U+\mathrm{CD}+D+\mathrm{WE})-(\mathrm{RE}+I)
$$

where SLC is the sea level change, $G$ is the change due to groundwater mining, $U$ is the change due to increased runoff from urbanization, $\mathrm{CD}$ is the change due to water release from combustion of fossil fuels and decomposition of biomass, $D$ is the change due to increased runoff from deforestation, WE is the change due to drainage of wetlands, $\mathrm{RE}$ is the change due to impoundment in reservoirs, and $I$ is the change due to irrigation. From equation (2), we note that only reservoirs and irrigation have negative contributions (leading to sea level drop), while the others are positive (leading to sea level rise). In this section we examine in more detail each of these contributions, and following Gornitz [2001], we first consider processes that increase sea level and then processes that reduce it. In all cases the associated sea level change results from a change in runoff.

\subsubsection{Processes That Increase Sea Level}

[41] Groundwater mining is the withdrawal of underground water confined in aquifers. Estimates have been provided for the volume of groundwater withdrawn annually in selected countries [Shiklomanov, 1997]. It appears that the amount of groundwater mining corresponds to $0.55-0.64 \mathrm{~mm} / \mathrm{yr}$ between 1990 and 1995 . Only part of the withdrawn water contributes to runoff; hence sea level rise is $0.1-0.3 \mathrm{~mm} / \mathrm{yr}$, the remaining water being used for consumption.

[42] Urbanization exerts a strong impact on hydrology in several ways. Because vegetated areas are replaced by impermeable pavements and other structures, this leads to increased surface runoff, reduced infiltration, and a fall in the water table level. Unfortunately, global quantitative data on the effects of urbanization are lacking. Gornitz [2001] provides an estimate in the range of $0.3-0.38 \mathrm{~mm} / \mathrm{yr}$, but no information is available on the associated uncertainty, which may be large.

[43] The combustion of fossil fuels and burning tropical forests release water into the atmosphere that is further exchanged with the oceans through the carbon cycle. Such a contribution to sea level rise is very poorly quantified, between $-0.06 \mathrm{~mm} / \mathrm{yr}$ and $0.07 \mathrm{~mm} / \mathrm{yr}$, with a medium value of $0.01 \mathrm{~mm} / \mathrm{yr}$. Deforestation contributes to a decrease in evapotranspiration, reduced soil infiltration, and increased runoff. For the recent years, Gornitz [2001] estimates a contribution of $0.09 \mathrm{~mm} / \mathrm{yr}$ sea level rise to increased runoff induced by deforestation.

\subsubsection{Processes That Decrease Sea Level}

[44] Sequestration of water in reservoirs and man-made lakes, preventing it from flowing into the ocean through the hydrographic network, has the greatest negative effect on sea level. Chao [1995] and Shiklomanov [1997] reported an almost linear rate of increase of reservoir capacity since 1950, which in the mid-1990s amounted to $6000 \mathrm{~km}^{3}$. Such an amount would produce a global sea level fall of $\sim 0.3 \mathrm{~mm} / \mathrm{yr}$. In addition, dam building has accelerated in recent years, especially in developing countries, contributing another $0.05 \mathrm{~mm} / \mathrm{yr}$ sea level fall. Besides the direct effect of water sequestration, there are indirect effects due to evaporation and infiltration (seepage losses). The latter effect may be important although very little data exist to quantify it at a global scale. Gleick [1992] estimates an average annual seepage loss of $\sim 5 \%$ of the reservoir volume. Gornitz [2001] uses this as a basis (with 10\% uncertainty) and proposes a water loss corresponding to $0.56-0.81 \mathrm{~mm} / \mathrm{yr}$ sea level drop. 
[45] Irrigation is another process that potentially contributes to sea level drop. In fact, irrigation is the main consumer of worldwide freshwater resources (up to $70 \%$ according to World Resources Institute, 1998, see http:// www.wri.org). As for reservoirs, water loss due to irrigation results from seepage into the ground and evapotranspiration by plant cultivation. Infiltration of water into the soil would lead to $0.4-0.5 \mathrm{~mm} / \mathrm{yr}$ sea level drop, while evapotranspiration would contribute another $0.12 \mathrm{~mm} / \mathrm{yr}$.

[46] From the processes briefly discussed above, we note that reservoirs and irrigation are two large contributors to sea level drop: approximately $-1 \pm 0.2 \mathrm{~mm} / \mathrm{yr}$ for reservoirs and $-0.56 \pm 0.1 \mathrm{~mm} / \mathrm{yr}$ for irrigation. Among the positive contributions the largest are urbanization $(0.34 \pm$ $0.04 \mathrm{~mm} / \mathrm{yr})$ and groundwater mining $(0.2 \pm 0.1 \mathrm{~mm} / \mathrm{yr})$. The net effect is negative (sea level drop), amounting to $-0.91 \pm 0.45 \mathrm{~mm} / \mathrm{yr}$. The large uncertainty, which is $\sim 50 \%$ of the estimated contribution, reflects the lack of global quantitative information on the processes involved. The above estimate $(=-0.91 \mathrm{~mm} / \mathrm{yr})$ is significantly greater than that quoted by Church et al. [2001], who give a value of $-0.35 \pm 0.70 \mathrm{~mm} / \mathrm{yr}$.

\subsection{Contributions Due to the Melting of Mountain Glaciers}

[47] There is considerable evidence that worldwide mountain glaciers have retreated during the past century as a result of global warming. Continental glaciers (other than the Greenland and Antarctica ice sheets) correspond to only a small fraction of the total land ice surface but represent the second largest contribution to the 20th sea level rise after thermal expansion. Mountain glaciers are sensitive indicators of climate variability. Compared to the Greenland and Antarctic ice sheets, mountain glaciers respond more quickly to climate change. Church et al. [2001] summarize estimates of historical global glacier contributions. These are mainly based on mass balance studies of a handful of representative glaciers on a regional basis. Depending on the surveying period, these estimates range between 0.2 and $0.4 \mathrm{~mm} / \mathrm{yr}$ in terms of sea level rise equivalent. Over the past decades, loss of glacier volume has been reported in many regions worldwide [Dyurgerov and Meier, 2000]. For those glaciers surveyed since the end of the 19th century, one notes that the mass decrease is not steady. An increased rate of loss occurred during the 1970s and more recently during the 1990s. In a recent compilation, Dyurgerov [2002] gathered mass balance results collected during the past 40 years for 260 glaciers [see also Dyurgerov and Meier, 2000]. Their distribution covers most of the primary ice-covered areas; however, continuous mass balance observations on time spans longer than 20 years are available for only a small number of glaciers ( $\sim 40$, most of them located in the Northern Hemisphere). Emphasizing the period 1961-1998 when data are more numerous and averaging the mass balance of all glaciers within six major glacier regions of the Northern Hemisphere (plus a few subregions), Dyurgerov and Meier [2000] provide an average decrease of $-147 \mathrm{~mm} / \mathrm{yr}$ in water equivalent, which

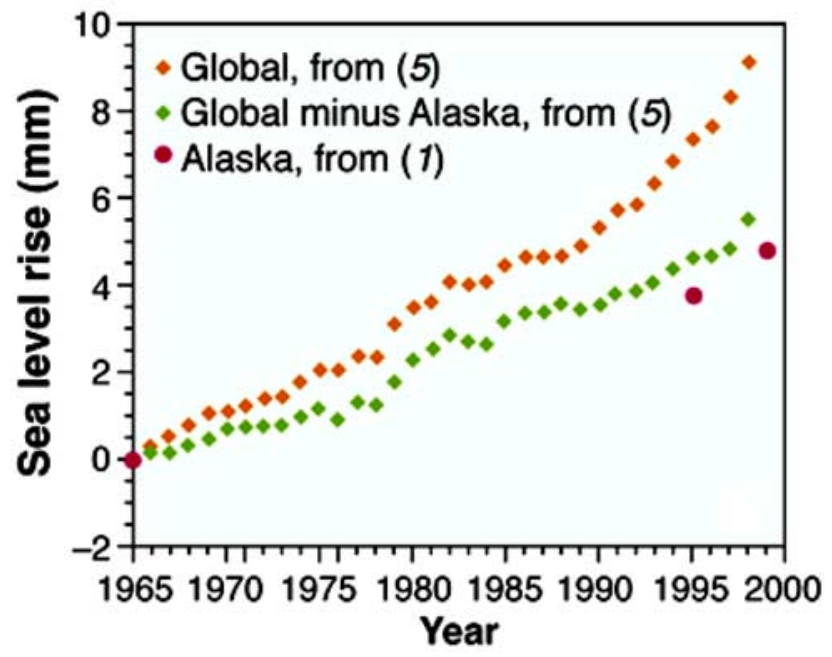

Figure 12. Global mean sea level variations since 1965 that result from mountain glacier melting, including the Alaskan glaciers. Reprinted with permission from Meier and Dyurgerov [2002]. Copyright 2002 American Association for the Advancement of Science. Numbers 1 and 5 in Figure 12 refer to Arendt et al. [2002] and Dyurgerov [2002], respectively.

corresponds to $0.27 \mathrm{~mm} / \mathrm{yr}$ global mean sea level rise. In this compilation the world's largest glaciers (in Alaska, Patagonia, and central Asia) are poorly represented. Recently, Arendt et al. [2002] have provided new estimates of the contribution of Alaska glaciers to sea level rise by measuring volume and area change of 67 glaciers $(2 \%$ of glaciers in Alaska) using airborne laser altimetry for 19931996 and conventional aerial topographic photographs acquired in the 1950s to early 1970 s. These observations revealed that most Alaskan glaciers have lost mass from the mid-1950s to the mid-1990s by an amount that corresponds to $0.14 \pm 0.04 \mathrm{~mm} / \mathrm{yr}$ sea level rise. Since the time span of the Alaskan glacier survey roughly corresponds to Dyurgerov and Meier's study, we can sum the two estimates, which leads to $0.41 \mathrm{~mm} / \mathrm{yr}$ sea level rise for the contribution of mountain glaciers, including Alaskan glaciers, for the past 40 years. Figure 12 (from Meier and Dyurgerov [2002] and also presented by Dyurgerov [2002]) shows the sea level curve since 1965 that results from mountain glacier melting, including the Alaskan glaciers. The rate of sea level rise $(0.41 \mathrm{~mm} / \mathrm{yr})$ reported above is based on that curve.

[48] In their study, Arendt et al. [2002] report resurveying results from airborne laser altimetry since 1999 for 28 Alaskan glaciers. They noticed an accelerated rate of mass loss in comparison to the previous 40 years. For the recent years the sea level rise equivalent amounts to $0.27 \pm$ $0.10 \mathrm{~mm} / \mathrm{yr}$. According to Arendt et al. [2002] the rapid glacier wastage observed in Alaska for most glaciers (but not all) is partly linked to climate warming, but other factors involving unstable glacier dynamics are also thought to play some role. If the rate of global glacier melting estimated by Dyurgerov and Meier [2000] and Dyurgerov [2002] for $1961-1998$ is assumed to be valid for the past 5 years, then adding the $0.27 \mathrm{~mm} / \mathrm{yr}$ for the recent contribution of 
Alaskan glaciers leads to a total of $0.55 \mathrm{~mm} / \mathrm{yr}$ recent sea level rise due to mountain glaciers.

[49] Recently, Rignot et al. [2003] showed that Patagonia ice fields have lost mass during the last 3 decades, especially in recent years. For the period 1995-2000 they estimate the equivalent sea level rise to be $0.10 \pm 0.01 \mathrm{~mm} / \mathrm{yr}$. Clearly, mountain glaciers, together with thermal expansion, are important components contributing to sea level rise.

\subsection{Contributions From the Melting of Polar Ice}

[50] The contribution of Greenland and Antarctica ice melting/accumulation to global sea level change is still rather uncertain. These two ice sheets contain $99 \%$ of the freshwater available on Earth, and if totally melted, they would raise global sea level by $70 \mathrm{~m}$. Thus the melting of only a very small fraction of the ice sheets is enough to raise sea level by a significant amount. The Greenland and Antarctic ice sheets have very different climatic regimes that result from differences in land-sea distribution and continental elevation. Water mass loss from Antarctica occurs primarily through basal melting of the ice shelves and iceberg calving. Surface melting is weak. In Greenland, melting occurs through both surface runoff and iceberg calving. The mass balance of the ice sheets depends on both the long-term melting since the last deglaciation that started about 18,000 years ago and on recent global climate change. Separating the two signals is difficult and not yet well controlled. There are several methods to estimate the mass balance of the ice sheets.

[51] 1. Estimate the individual mass balance terms from direct observations (snow accumulation from precipitation and mass loss from surface and basal melting and iceberg calving) and determine the mass budget.

[52] 2. Directly monitor the surface elevation changes over time, further expressed in terms of volume change. This method needs to account for snow compaction and requires knowledge of the change in vertical land motion due to postglacial rebound and other tectonic or loading deformations.

[53] 3. Numerically model the past history of the ice sheets over a glacial cycle to quantify their long-term dynamical response to glacial/interglacial conditions. The main forcing term of these models is past temperature records derived from ice cores.

[54] 4. Numerically model the present-day response of the ice sheets to global climate change using climate models.

[55] The Church et al. [2001] compilation of the above methods provides the sea level change equivalent values shown in Table 1. Finally, Church et al. use as best estimates values based on numerical modeling, with a total (both ice sheets) long-term component in the range $0.0-0.5 \mathrm{~mm} / \mathrm{yr}$, a present-day Greenland component in the range $0.0-$ $0.1 \mathrm{~mm} / \mathrm{yr}$, and a present-day Antarctica component in the range $-0.2-0.0 \mathrm{~mm} / \mathrm{yr}$. The sum of these three terms has a central value of $0.2 \mathrm{~mm} / \mathrm{yr}$ with an uncertainty of $0.6 \mathrm{~mm} / \mathrm{yr}$.

[56] Recently, Rignot and Thomas [2002] have reported new estimates of the mass balance of the polar ice sheets based on remote sensing observations conducted during the
TABLE 1. Estimates of Polar Ice Contributions to Global Sea Level Change

\begin{tabular}{|c|c|c|}
\hline & Greenland & Antarctica \\
\hline Mass balance studies, $\mathrm{mm} / \mathrm{yr}$ & $0.12 \pm 0.15$ & $-0.5(?)$ \\
\hline Surface elevation measurements, $\mathrm{mm} / \mathrm{yr}$ & 0.13 & $\mathrm{NA}^{\mathrm{a}}$ \\
\hline Numerical long-term modeling, mm/yr & $-0.1-0.0$ & $0.1-0.5$ \\
\hline Numerical present-day modeling, $\mathrm{mm} / \mathrm{yr}$ & $0.0-0.1$ & $-0.2-0.0$ \\
\hline
\end{tabular}

past decade and new mass budget estimates. Mass balance estimates have also been provided for high-elevation parts of the Greenland ice sheet. These studies, based on repeated GPS measurements between 1993 and 1997 at stations located around the Greenland ice sheet, report that highelevation (above $2000 \mathrm{~m}$ ) areas of the Greenland ice sheet have been almost in balance, but major changes have occurred in the southern part of the ice sheet, with rapid thinning in the east and thickening in the west. Southwest thickening is thought to represent a long-term dynamic response of the ice sheet rather than recent changes in accumulation rates [Thomas et al., 2000]. These highelevation results are in good agreement with those based on repeated airborne laser altimetry surveys conducted during the 1990s [Abdalati et al., 2001; Davis et al., 2000; Krabill et al., 2000]. In contrast to high-elevation areas, at lower elevations, thinning predominates, especially in southern Greenland [Krabill et al., 2000]. Krabill et al. combine airborne laser altimetry and GPS measurements between 1993 and 1999 and show that in recent years, coastal regions have thinned rapidly, especially along channels associated with outlet glaciers. Glacier thinning is the most pronounced in the southeast. Krabill et al. [2000] estimate the ice volume reduction in coastal regions is $51 \mathrm{~km}^{3} / \mathrm{yr}$, corresponding to $0.13 \mathrm{~mm} / \mathrm{yr}$ sea level rise. No error bar is provided with this estimate, but the authors consider it as a lower bound, mainly because it is based on a small number of surveyed glaciers (trends for nonsurveyed glaciers are deduced from numerical modeling). Observations by Dickson et al. [1988] suggest large recent changes in the North Atlantic and the Arctic that may have increased basal melting rates [Rignot and Thomas, 2002]. Other effects, such as increased basal lubrication associated with surface meltwater, contribute to glacier thinning [Zwally et al., 2002] and hence sea level rise.

[57] Over the Antarctica ice sheet it is harder to make use of remote sensing techniques because of its large area, remote location, polar latitudes, and extreme weather conditions. Thus mass budget estimates are available for only a few limited regions, and elevation change measurements have been conducted for the northern part of the ice sheet only. Nevertheless, using new published data on the Antarctica ice sheet (new snow accumulation rates, a topographic model of the ice sheet, radar images, interferometric synthetic aperture radar-based glacier velocities, etc.), Rignot and Thomas [2002] provide mass budget estimates of 33 Antarctic glaciers, which include 25 of the 30 largest ice producers. They found a net budget (accumulation minus outflow) of $-48 \pm$ $14 \mathrm{~km}^{3} / \mathrm{yr}$ for West Antarctica and $+22 \pm 23 \mathrm{~km}^{3} / \mathrm{yr}$ for East 


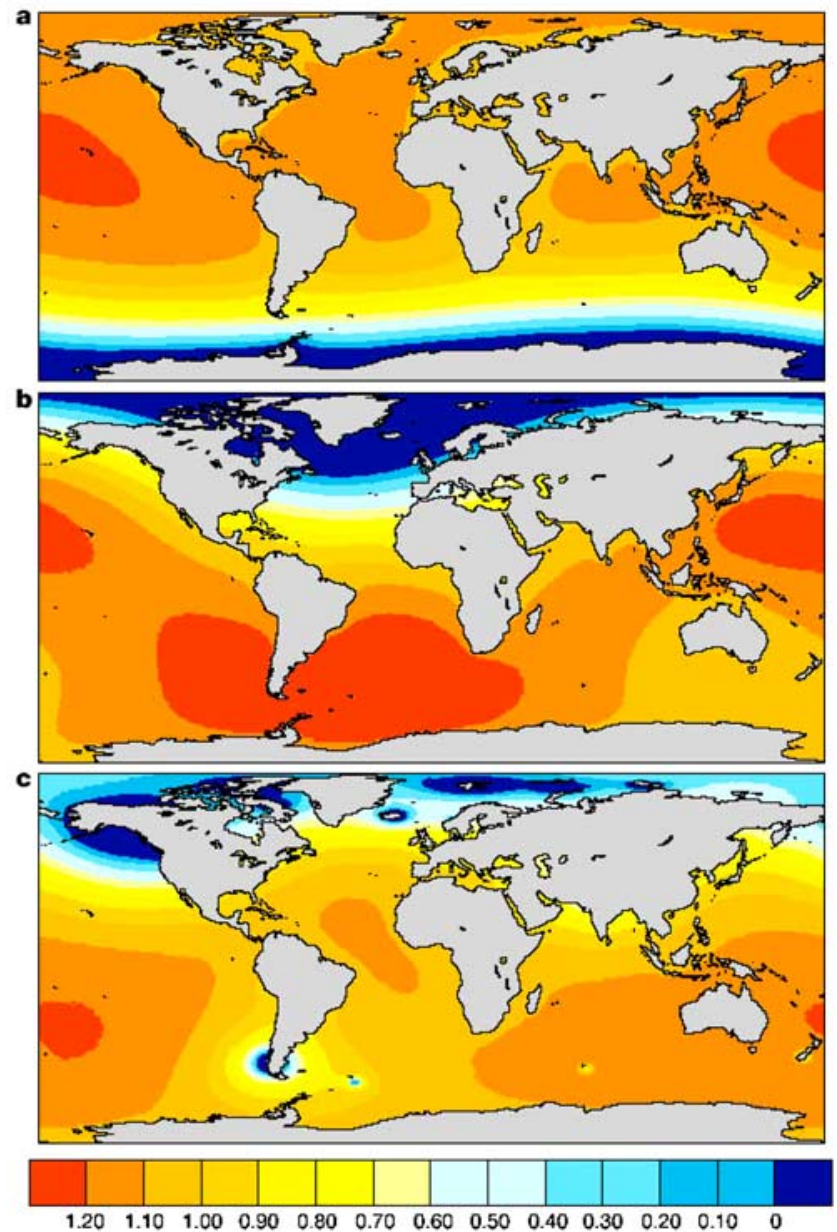

Figure 13. Patterns of sea level change resulting from the melting of ice in (a) Antarctica, (b) Greenland, and (c) mountain glaciers. Units are $\mathrm{mm} / \mathrm{yr}$ for a $1-\mathrm{mm} / \mathrm{yr}$ ice melt contribution. From Mitrovica et al. [2001] (used with permission from Nature (http://www.nature.com)).

Antarctica. In terms of sea level change this gives $0.16 \pm$ $0.05 \mathrm{~mm} / \mathrm{yr}$ for the West Antarctic contribution and $0.06 \pm$ $0.06 \mathrm{~mm} / \mathrm{yr}$ for East Antarctica. The small value and large uncertainty associated with the eastern part reflects the fact that East Antarctica is likely in balance, with no contribution to present-day sea level rise (E. Rignot, personal communication, 2003). Besides, West Antarctic mass loss results mainly from the strongly negative imbalance of the Amundsen Sea Embayment, with several glaciers of this sector experiencing very high bottom melt rates. Rignot and Thomas [2002] suggested that those rates may have increased in the recent past, thereby thinning the ice shelves. By reducing their buttressing of the ice streams, thinning of the ice shelves may have, in turn, accelerated their mass imbalance. This may result from thermal forcing from the ocean through intrusion of warm Circumpolar Deep Water across the continental shelf, as recent observations indicate warmer ocean conditions [Jacobs et al., 2002]. Rapid ice mass loss may indeed reflect a reaction to warmer ocean conditions.

[58] The recent observations of the ice sheets' mass balance lead to a total contribution to sea level rise of $\sim 0.3 \pm 0.1 \mathrm{~mm} / \mathrm{yr}$ for the past decade. While not signifi- cantly different from the value quoted by Church et al. [2001], it likely represents a lower bound since contributions from Greenland and West Antarctica are currently considered to be underestimated as discussed above. Moreover, there are several indices suggesting an acceleration of the retreat of the Antarctic Peninsula ice shelves in recent years [e.g., De Angelis and Skvarca, 2003], suggesting that their contribution to sea level may not be negligible (E. Rignot, personal communication, 2003).

[59] A final point is that if the polar ice sheets or mountain glaciers melt appreciably, it may be possible to detect this indirectly from measurements of sea level change over the ocean. As has been recently described [Mitrovica et al., 2001; Plag and Juttner, 2001; Tamisiea et al., 2001], the melting of ice in these regions will actually lower the corresponding geoid, and thus sea level around the margins of these regions will actually fall (Figure 13). While the sea level record from $\mathrm{T} / \mathrm{P}$ is too short to detect this geographic pattern of sea level change, in the future satellite altimetry will provide an important tool for detecting the pattern of sea level change resulting from the melting of large ice sheets and mountain glaciers [Tamisiea et al., 2003].

\subsection{Land Water Contribution Due to Change in Continental Water Cycle}

[60] Besides the anthropogenic component, there is another contribution not discussed by Church et al. [2001]: interannual/decadal change in land water content that is associated with modifications of the global water cycle. Indeed, sea level is expected to change in response to the amount of water mass exchanged between oceans and land under climate change. The continental water budget includes water (both liquid and solid) stored in the root zone (soil moisture) and underground aquifers and in the snowpack and surface water reservoirs (lakes, rivers, floodplains, and wetlands). However, in spite of their major influence on climate variability and on human activities the global distribution and temporal variability of continental water (soil moisture and underground waters) and snow are unknown because in situ observations do not exist over most of the world.

[61] Thus present global estimates of land water storage essentially rely on hydrological models, coupled with atmosphere/ocean global circulation models and/or forced by observations. These models estimate the variation in land water storage by solving a water budget equation that relates changes in land water mass $(W)$ with time $(t)$ to precipitation $(P)$, evapotranspiration $(E)$, and runoff $(R)$ :

$$
\frac{d W}{d t}=P-E-R
$$

These land surface schemes are driven by spatiotemporally varying mass and energy fluxes, the main forcing being precipitation. Model outputs include gridded time series of soil moisture, snow depth, surface runoff, and, occasionally, groundwater.

[62] Early models published during the 1980s and early 1990s derived evapotranspiration from simple empirical formulations and used monthly meteorological forcing 
LaD (v2) Ground water + Soil moisture + Snow

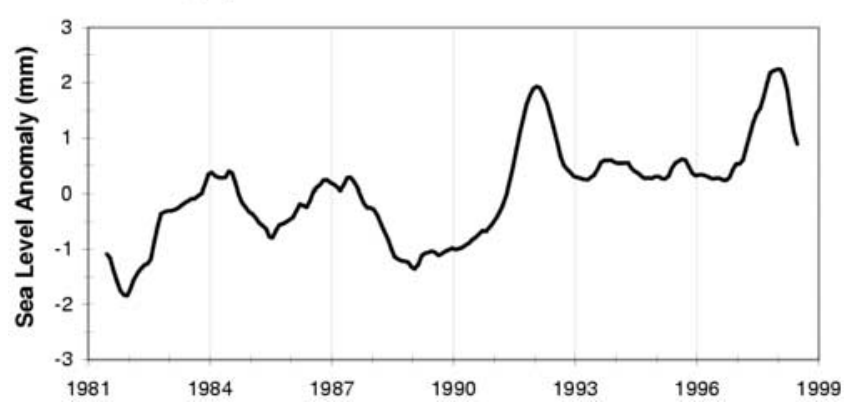

Figure 14. Equivalent sea level variations due to change in land water and snow mass over 1981-1998. LaD stands for Land Dynamics model. From Milly et al. [2003]. Copyright 2003 National Academy of Sciences, U.S.A.

[Huang et al., 1996; Mintz and Serafini, 1992; Willmott et al., 1985]. However, recent models are based on sophisticated land surface schemes describing soil/vegetation/atmosphere energy and mass transfers using high-frequency (typically 6 hours) meteorological forcing. This is the case for models developed in the context of the Global Soil Wetness Project (GSWP) [Dirmeyer et al., 1999], whose objective was to study the feasibility of producing global soil wetness data that overcome the deficiencies of former models. Global hydrological products derived during GSWP cover only 2 years (1987-1988); thus, while they are very useful to estimate the annual contribution of land waters to the global mean sea level, they cannot be used to study the interannual variability.

[63] The Land Dynamics model developed by Milly and Shmakin [2002] is one of the few models offering information on the interannual variability in land water storage. The model, which provides global $1^{\circ} \times 1^{\circ}$ monthly gridded time series for 1981-1998 of root zone soil water, underground water, and snow depth, can be used to quantify for the first time the contributions of time-varying storage of terrestrial waters in response to climate change. Figure 14 [Milly et al., 2003] shows the corresponding equivalent sea level variations. A small positive trend, of $\sim 0.12 \mathrm{~mm} / \mathrm{yr}$, is observed. This corresponds to an overall decrease in the amount of water mass stored on land. However, Figure 14 shows that interannual fluctuations dominate the signal. For example, over 1990-1998 the decrease in land water storage corresponds to $0.25 \mathrm{~mm} / \mathrm{yr}$ sea level rise. Underground water is the major contributor on interannual timescales. This is unlike the seasonal timescale where snow mass change contributes to $\sim 70 \%$ of the observed global mean sea level change after correcting for steric effects [Cazenave et al., 2000; Chen et al., 1998; Minster et al., 1999].

\section{ASTRONOMICAL AND GEOPHYSICAL CONSTRAINTS ON PRESENT-DAY SEA LEVEL CHANGE}

[64] Being sensitive to surface mass redistribution, changes in the Earth's rotation rate (referred to as changes in the length of day (LOD)), and/or changes in the Earth's gravitational oblateness $\left(J_{2}\right)$ also provide indirect constraints on ocean mass change due to meltwater mass exchange between mountain glaciers or ice sheets and the oceans. Several authors [Johnston and Lambeck, 1999; Munk, 2002; Peltier, 1998; Sabadini and Vermeersen, 2002] have shown that temporal variations of the Earth's rotation parameters (angular velocity and polar motion), as well as other geodetic parameters (e.g., Earth's oblateness), can offer independent constraints on the range of present-day eustatic sea level rise (i.e., water mass change in ocean basins). These observations are the following. (1) The nontidal acceleration of Earth's rotation (or, equivalently, the secular decrease of the length of day (LOD)), based on eclipse observations during antiquity (from 500 B.C.) and historical period up to the present day [Stephenson and Morrison, 1995], amounts to an LOD change of $-0.6 \mathrm{~ms} /$ century. (2) The secular decrease of the Earth's oblateness (as described by the $J_{2}$ coefficient of the spherical harmonic expansion of the gravity field) observed by geodetic satellites during the past 25 years [Cox and Chao, 2002] is approximately $-2.8 \times 10^{-11} / \mathrm{yr}$ (Figure 15). (3) The observed secular motion of the Earth's rotation pole (true polar wander) is toward Canada [Dickman, 1979; McCarthy and Luzin, 1996].

[65] These three observations have been generally explained by postglacial rebound [Johnston and Lambeck, 1999; Kaufmann and Lambeck, 2000; Peltier, 1998; Peltier and Jiang, 1996; Sabadini and Vermeersen, 2002; Vermeersen et al., 1997]. Indeed, viscous mantle material flowing from low latitudes toward high latitudes in response to the last deglaciation that started 18,000 years ago led to large-scale mass redistribution within the Earth system, hence causing a change of the Earth's inertia tensor. Because the Earth is deformable, the rotation rate and rotation axis adjust themselves in order to conserve angular momentum. In the absence of other torques, changes in LOD are directly proportional to changes in the polar moment of inertia $(C)$.

[66] The Earth's oblateness, $J_{2}$, represents the slight equatorial bulge of the Earth. It is proportional to the difference between the polar and equatorial moments of inertia. Thus, as

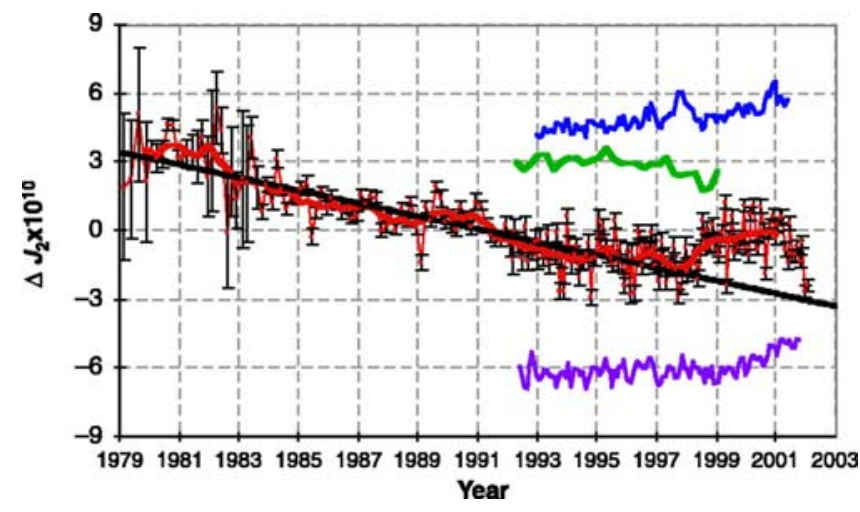

Figure 15. Monthly variations of the Earth's gravitational oblateness $\left(J_{2}\right)$ based on satellite laser ranging data to numerous geodetic satellites from 1979 to 2001. Reprinted with permission from Cox and Chao [2002]. Copyright 2002 American Association for the Advancement of Science. 
for $\mathrm{LOD}$, any change of $J_{2}$ is proportional to a change of $C$. It has been noted that observed changes in LOD and $J_{2}$ provide the same numerical change in $C$, suggesting that the two observations are independent measures of the same physical process on two different timescales: the past 2500 years and the past 25 years. Considering the very long time span (2500 years) under consideration, the best candidate is evidently postglacial rebound.

[67] A number of postglacial rebound models have been developed during the past 2 decades [e.g., Lambeck and Johnston, 1998; Mitrovica and Forte, 2004; Peltier, 1998]. The basis for these models is the estimation of the profile of mantle viscosity with depth using geological observations of relative sea level change associated with the last deglaciation. The models describe the global deformation of a viscoelastic Earth in response to the coupled effects of ice sheet loading history and complex redistribution of meltwater load into the oceans. Such an approach requires a physical formalism describing the Earth's deformation to surface loading, models and data for the changing ice sheets, and knowledge of the volume and geometry of the oceans through time, as well as elastic and depth-dependent viscous parameters for the lithosphere and the layered mantle. In general, the ice sheet loading history is an input of the models. The main unknown parameters are viscosity values within mantle layers whose number and thickness are prescribed. These parameters are estimated by comparing observations and predictions of relative sea level change at various sites over the past 18,000 years. Secular changes of LOD and $J_{2}$ also contain information on the depth-varying mantle viscosity. Model predictions for $J_{2}$ have been developed [e.g., Johnston and Lambeck, 1999; Peltier, 1998; Sabadini and Vermeersen, 2002]. Figure 16 from Sabadini and Vermeersen [2002] shows theoretical $J_{2}$ variations due to postglacial rebound as a function of lower mantle viscosity. The upper mantle viscosity is fixed here at $5 \times 10^{20} \mathrm{~Pa}$ s. We see that intersection between the theoretical curve and $J_{2}$ observations leads to a lower mantle viscosity around $2 \times$ $10^{21} \mathrm{~Pa}$ s, a value that roughly agrees with the Peltier [1998] estimates. Depending on the details of the modeling, the main result is that observed $J_{2}$ can be explained by a lower mantle viscosity (in the range $1-5 \times 10^{21} \mathrm{~Pa} \mathrm{~s}$ ) that also fits geological observations of Holocene sea level variations.

[68] Recently, postglacial rebound modelers [Lambeck and Johnston, 1998; Peltier, 1998; Sabadini and Vermeersen, 2002] have also taken into account meltwater input to the world oceans caused by present-day melting of the ice sheets. Indeed, the latter effect also changes the polar moment of inertia. Figure 16 illustrates the effect of accounting for present-day eustatic sea level rise due to Antarctica and Greenland melting in addition to postglacial rebound. In this model a $1.5-\mathrm{mm} / \mathrm{yr}$ eustatic sea level rise due to $500 \mathrm{Gt} / \mathrm{yr}$ of Antarctica melting plus $140 \mathrm{Gt} / \mathrm{yr}$ of Greenland melting is accounted for. We see that to simultaneously explain the observed secular decrease of $J_{2}$ by postglacial rebound plus present-day ice cap melting, an increase of the lower mantle viscosity by an order of magnitude (thus in the range 1 to $5 \times$ $10^{22} \mathrm{~Pa} \mathrm{~s}$ ) must be invoked.

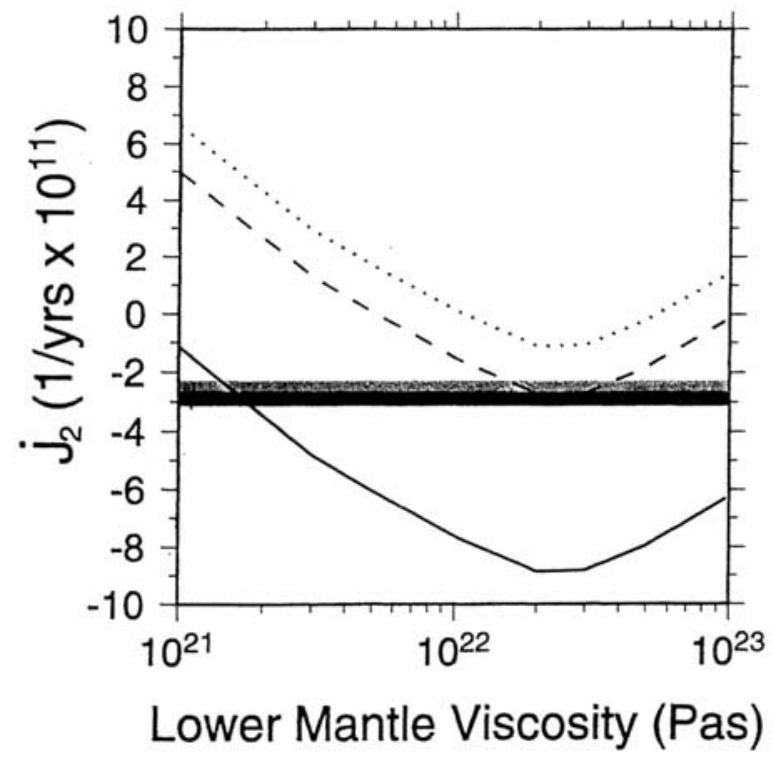

Figure 16. Theoretical $J_{2}$ variations due to postglacial rebound as a function of lower mantle viscosity. The upper mantle viscosity is fixed at $5 \times 10^{20} \mathrm{~Pa} \mathrm{~s}$. The thin solid line represents the theoretical $\mathrm{J} 2$ due to postglacial rebound only, while dashed and dotted lines account for Antarctica melting and Antarctica plus Greenland melting, respectively, in addition to postglacial rebound. The horizontal thick line represents the observed J2 value. From Sabadini and Vermeersen [2002].

[69] Such a value is not ruled out by Earth models that use observations of the nonhydrostatic long-wavelength geoid. The long-wavelength geoid is highly sensitive to internal density distribution and to the radial stratification of mantle viscosity. In the 1980 s, mantle flow models were developed to derive mantle viscosity profiles with depth [Forte and Peltier, 1991; Hager and Clayton, 1989]. These models solve for basic dynamical equations of mantle convection to determine dynamically maintained deformations of the main mantle interfaces under convective stresses and to infer the long-wavelength geoid produced by the mass anomalies associated with the boundary deflections. Mantle convection is assumed to be driven by lateral density anomalies derived from seismic tomography. The computed geoid is strongly dependent on viscosity contrasts at the main mantle interfaces. Comparing with the observed (nonhydrostatic) geoid leads to solutions for the radial viscosity structure. Numerous inversions for the mantle viscosity have been proposed during the past 15 years, and some general features have been inferred, such as a noticeable increase of the mantle viscosity from the upper mantle to the lower mantle. However, the exact value for the viscosity contrast between the upper and lower mantle is still a matter of debate, as are the number and average depth of viscosity interfaces and even the signs of some viscosity contrasts.

[70] In a recent study involving a joint inversion for geoid and surface topography, Panasyasuk and Hager [2000] assessed solutions for the mantle viscosity structure by investigating various sources of data errors and model 
deficiencies. Using 22 different density anomaly models, their inversions led to three very different families of mantle viscosity profiles providing similar fits to the observables. The only common feature between the three solution families is the steady increase of the lower mantle viscosity down to the core-mantle boundary by about an order of magnitude. This study helps clarify the differences in the numerous viscosity profiles published over the past 2 decades, since most of them fall within one of the three families. It shows in particular the important dependence of the solutions on the model density anomalies.

[71] What may be the consequence of the uncertain mantle viscosity structure in the $J_{2}$ interpretation? The answer is unclear. Besides, assuming that $J_{2}$ would be affected by ice sheet melting only (in addition to postglacial rebound) is somewhat simplistic. Other sources of largescale surface mass redistribution can affect $J_{2}$ on a secular timescale. For example, large-scale, pseudosecular change in land water storage, ocean mass, or atmospheric air mass associated with global climate change may exhibit a zonal pattern that may give rise to a $J_{2}$-like signature.

[72] Recently, the secular decrease in $J_{2}$ observed from precise satellite orbits for $\sim 25$ years suddenly stopped (see Figure 15). Indeed, in early 1998 the $J_{2}$ trend reversed [Cox and Chao, 2002], indicating a large-scale mass redistribution from high latitudes to the equatorial regions. Several mechanisms might explain such an observation: melting of the polar ice caps, melting of mountain glaciers, sudden change in material flow at the top of the fluid outer core, or large-scale mass redistribution in the oceans (see Cox and Chao [2002] and Cazenave and Nerem [2002] for a discussion). A recent investigation by Dickey et al. [2002] proposes that the reversed trend in $J_{2}$ would primarily result from a recent surge in the melting of mountain glaciers and to a lesser extent from mass redistribution in the southern Pacific and Indian Oceans. While large-scale ocean mass redistribution within the oceans would not give rise to a global mean sea level change, water flux from glacier melting would produce a positive signal in the global mean sea level. The global mean sea level curve derived from T/P observations (see Figure 5) does not show evidence of a sudden and significant increase in early 1998, although there was a large change about 1 year earlier during the ENSO event, which is thought to be mainly steric in origin. To account for an increased contribution from mountain glaciers since 1998 without changing the rate of sea level rise requires a significant decrease of thermal expansion compared to the previous years. This does not appear to be supported by recent results [Chambers, 2003; Lombard et al., submitted manuscript, 2004]. A recent acceleration of mountain glacier melting would cause a significant contribution to the observed sea level rise, unless another effect of opposite sign exists. In view of the still poorly understood causes of observed $J_{2}$, it seems unsafe to use this observation to constrain the amount of present-day meltwater reaching the oceans.

[73] With regard to true polar wander it appears that a $1.5 \mathrm{~mm} / \mathrm{yr}$ eustatic sea level rise contribution significantly degrades the consistency between observed and predicted motion, both in amplitude and direction. In addition, it cannot be excluded that present-day true polar wander partly results from totally different phenomena such as imperfectly compensated tectonic plate motions, mantle convection, and mantle avalanches across the lower mantle over geological time [e.g., Richards et al., 1999; Besse and Courtillot, 2002].

\section{SEA LEVEL BALANCE FOR THE PAST DECADE: A SYNTHESIS}

[74] We have seen that the rate of sea level rise based on tide gauge records for the past century ranges between 1 and $2 \mathrm{~mm} / \mathrm{yr}$ [Church et al., 2001]. We have also seen that for the past decade the rate of sea level rise measured by T/P altimetry amounts to $2.8 \pm 0.4 \mathrm{~mm} / \mathrm{yr}$. According to Peltier [1998], postglacial rebound causes a secular increase in the volume of the ocean basins, which, in turn, reduces global mean sea level by approximately $-0.3 \mathrm{~mm} / \mathrm{yr}$. To explain the T/P-based sea level rise in terms of climate factors, the postglacial rebound effect needs to be removed from the geocentric rate of sea level rise. Thus the corrected rate of sea level rise over the past decade is closer to $3.1 \mathrm{~mm} / \mathrm{yr}$, which is significantly larger than for the previous decades (in the range $1-2 \mathrm{~mm} / \mathrm{yr}$ ).

[75] A recent study by Woodworth et al. [2004] used the Hadley Center atmosphere ocean general circulation model to determine the steric sea level contribution for the 1990s, obtaining a value of $1.5 \mathrm{~mm} / \mathrm{yr} \pm 0.4 \mathrm{~mm} / \mathrm{yr}$. This model estimate is 3 times larger than the Church et al. [2001] and Antonov et al. [2002] values for the past decades. This suggests that thermal expansion has accelerated during recent years compared to the previous decades. The steric sea level acceleration seen since the early 1990s is possibly connected to the observed acceleration of glacier melting reported by Dyurgerov and Meier [2000], as well as the somewhat enhanced Greenland and West Antarctica melting [Rignot and Thomas, 2002] compared to observations in previous decades [Church et al., 2001]. We cannot exclude the possibility that enhanced ocean warming and ice melting reported for the past decade have a common origin related to stronger global warming. Sea level rise during the 1990s, a consequence of the latter two phenomena, is independent evidence of a large-scale change having affected the climate system during the last decade.

\section{FUTURE SEA LEVEL OBSERVATIONS}

[76] The 1990s was the decade in which we saw the emergence of satellite altimetry as the preferred technique for measuring long-term sea level change. With the successful launch of the Jason satellite in 2001 the continuation of the decade-long sea level time series established by T/P is assured. However, satellite geodesy promises to provide many new observations related to sea level change in the coming decade. 
[77] The launch of the Gravity Recovery and Climate Experiment (GRACE) in 2002 promises to provide an entirely new tool for studying sea level change. Eventually, it is hoped that GRACE will provide precise monthly estimates of the temporal changes in the Earth's gravitational field. It is expected to do this with a spatial resolution of $\sim 400 \mathrm{~km}$ and an accuracy of $1 \mathrm{~cm}$ water equivalent. Effectively, this will provide a means of monitoring the redistribution of water mass on the Earth's surface. Over the oceans these measurements will be equivalent to measuring changes in ocean bottom pressure, but by correcting for atmospheric pressure, measurements of ocean mass change can be constructed [Jayne et al., 2003; Nerem et al., 2004]. Over the continents, GRACE measurements can be used to monitor changes in the distribution of mountain glaciers, polar ice, water in aquifers, and other forms of water storage. The potential of the GRACE mission for making significant contributions to the study of sea level change has not yet been realized, but it is expected that improvements in the data processing will soon allow these types of studies. Clearly, GRACE has the potential to allow one to separate steric and mass variations in the oceans, when combined with satellite altimetry, as well as to determine the amount of water mass being contributed by the continents. It has also been demonstrated that GRACE will provide important improvements to estimates of mantle viscosity [Velicogna and Wahr, 2002], which would improve postglacial rebound models used to correct tide gauge sea level measurements and to predict relative sea level change.

[78] The launch of the Ice, Cloud, and Land Elevation Satellite (ICESAT) in 2002, with its laser altimeter on board, provides a method of monitoring the change in volume of the ice sheets in Greenland and Antarctica, thus constraining their contribution to long-term sea level change. While issues such as compaction and vertical crustal motion will complicate the interpretation of these measurements, studies have shown that combining ICESAT and GRACE data will yield important constraints on polar ice mass balance [Velicogna and Wahr, 2002; Wahr et al., 2000]. Since any sudden large change in sea level would have to arise from melting polar ice, the ICESAT measurements will be critical to long-term strategies to monitor sea level change.

[79] Improvements in ground-based satellite geodetic positioning technologies, such as GPS and DORIS, will also be beneficial to sea level change studies during the next decade. In particular, monitoring the vertical movement of tide gauges would be an important contribution for two reasons. First, vertical crustal motion is the dominate error source in tide gauge calibrations of satellite altimeters [Mitchum, 2000]. Second, provided that the crustal motion can be assumed to be uniform over the last 100 years, geodetic estimates of the rate of crustal motion at tide gauges can be used to improve estimates of historical sea level change as determined from the tide gauges.

[80] Perhaps the most important measurements for sea level change studies are those provided by satellite altimetry. By some estimates a 30-year time series of satellite altimetry may be required to detect an acceleration in the rate of sea level change [Nerem et al., 1999]. Thus it is important to note that in addition to Jason, there are plans to extend the time series with the launch of the Ocean Surface Topography Mission (which will also likely include an experimental wide-swath altimeter [Fu, 2003]) and eventually with operational altimetry collected by the National Polar-Orbiting Environmental Satellite System satellites.

\section{CONCLUSIONS}

[81] Our understanding of long-term sea level rise has changed considerably over the past decade. At the time of the second IPCC assessment [Houghton et al., 1996] the consensus estimate from the tide gauges was $1.5-2 \mathrm{~mm} / \mathrm{yr}$, and it was estimated that half of this was due to steric heating and the rest was due to the melting of polar ice and mountain glaciers. However, by the time of the third assessment [Houghton et al., 2001] the picture was much less clear, as the work of Levitus et al. [2000a] had shown the steric component was only $0.5 \mathrm{~mm} / \mathrm{yr}$, and the ice contributions were smaller still. There have been two recent proposals to resolve this dilemma. Cabanes et al. [2001b] have suggested that the tide gauge estimates of sea level rise are biased high by a factor of $2-3$ because of their poor spatial sampling. This would imply a huge recent acceleration of sea level rise to get to the corrected rate of $3.1 \mathrm{~mm} / \mathrm{yr}$ observed by altimetry. Alternatively, Miller and Douglas [2004] suggest that the tide gauges are not biased and that the eustatic contribution is $\sim 1.3 \mathrm{~mm} / \mathrm{yr}$, which is in agreement with recent estimates of global freshening of the ocean by Antonov et al. [2002] and Munk [2003]. This would suggest a historical rate of $1.8 \mathrm{~mm} / \mathrm{yr}$, which still requires a significant acceleration to get to the altimetric rate observed over the last decade. It would be fair to say that most scientists in the field prefer this most recent resolution to the dilemma, but the Cabanes et al. proposal is still a viable solution. Certainly, the altimetry and hydrographic data sets have proven that global mean sea level rise is not geographically uniform, and thus one must be careful with geographically sparse oceanographic data sets.

[82] We have more information about sea level change today than at any other time in human history. We have comprehensive historical data sets from tide gauge and hydrographic measurements that provide estimates of total sea level change and its component contributions. We have an improved understanding of postglacial rebound and models for predicting its effect on relative sea level change measurements. We also have precise geodetic techniques that are beginning to produce estimates of vertical crustal motion at or near tide gauges. Finally, we now have over a decade of precision satellite altimetry, which has provided unprecedented insight into recent changes in global mean sea level. Nevertheless, these tools seem to have raised more questions than they have answered. For example, satellite altimetry has given, for the first time, information about sea level change in open oceans and shown that sea level trends are not geographically uniform. While the exact causes of the observed patterns are still to be understood, such a result 
is of high importance when considering coastal impacts of sea level rise, some regions being clearly much more vulnerable than others. Another question that has been raised is if the historical tide gauge measurements have a significant bias due to poor spatial sampling. Compelling cases can be made both for and against such a bias. As the record from satellite altimetry lengthens, the importance of the tide gauge observations for sea level rise studies will have a lesser, though still important, role. However, for the next decade or two, tide gauge and hydrographic measurements will continue to be important as a baseline for climate change studies, and thus understanding the limitations of these data sets will be a critical component of sea level change science.

[83] ACKNOWLEDGMENTS. This article has benefited from the comments and discussions with the following people: John Antonov, Cecile Cabanes, Don Chambers, John Church, Kien DoMinh, Bruce Douglas, Marc Dyurgerov, Jay Famiglietti, Jonanthan Gregory, Kurt Lambeck, Eric Leuliette, Christian Le Provost, Pierre Yves Le Traon, Alix Lombard, Mark Meier, Laury Miller, Gary Mitchum, Jerry Mitrovica, Walter Munk, Eric Rignot, Mark Tamisiea, and Phil Woodworth. We would like to dedicate this paper to Christian Le Provost, who passed away in February 2004 when this paper was being prepared. In addition to his well-known work on modeling ocean tides, Christian made significant contributions to sea level observations, in particular in the context of GLOSS.

[84] The Editor responsible for this paper was Thomas Torgersen. He thanks three technical reviewers and one crossdisciplinary reviewer.

\section{REFERENCES}

Abdalati, W., W. Krabill, E. Frederick, S. Manizade, C. Martin, J. Sonntag, R. Swift, R. Thomas, W. Wright, and J. Yungel (2001), Outlet glacier and margin elevation change: Near-coastal thinning of the Greenland ice sheet, J. Geophys. Res., 106(D24), $33,729-33,742$.

Antonov, J. I., S. Levitus, and T. P. Boyer (2002), Steric sea level variations during 1957-1994: Importance of salinity, J. Geophys. Res., 107(C12), 8013, doi:10.1029/2001JC000964.

Arendt, A. A., K. A. Echelmeyer, W. D. Harrison, C. S. Lingle, and V. B. Valentine (2002), Rapid wastage of Alaska glaciers and their contribution to rising sea level, Science, 297, 382-386.

Besse, J., and V. Courtillot (2002), Apparent and true polar wander and the geometry of the geomagnetic field over the last $200 \mathrm{Myr}$, J. Geophys. Res., 107(B11), 2300, doi:10.1029/2000JB000050.

Cabanes, C. (2003), Les variations du niveau moyen global et regional de la mer observation par altimetrie satellitale et maregraphie, analyse et interpretation physique, thèse de doctorat, Univ. Paul Sabatier, Toulouse III, Toulouse, France.

Cabanes, C., A. Cazenave, and C. Le Provost (2001a), Sea level change from TOPEX-Poseidon altimetry for 1993-1999 and possible warming of the southern oceans, Geophys. Res. Lett., 28(1), 9-12.

Cabanes, C., A. Cazenave, and C. Le Provost (2001b), Sea level rise during past 40 years determined from satellite and in situ observations, Science, 294, 840-842.

Cazenave, A., and R. S. Nerem (2002), Geophysics: Redistributing Earth's mass, Science, 297, 783-784.

Cazenave, A., K. Dominh, M. C. Gennero, and B. Ferret (1998), Global mean sea level changes observed by TOPEX-Poseidon and ERS-1, Phys. Chem. Earth, 23(9-10), 1069-1075.

Cazenave, A., K. Dominh, F. Ponchaut, L. Soudarin, J.-F. Cretaux, and C. Le Provost (1999), Sea level changes from TOPEX-
Poseidon altimetry and tide gauge, and vertical crustal motions from DORIS, Geophys. Res. Lett., 26(14), 2077-2080.

Cazenave, A., F. Remy, K. Dominh, and H. Douville (2000), Global ocean mass variation, continental hydrology and the mass balance of the Antarctic ice sheet at the seasonal time scale, Geophys. Res. Lett., 27, 3755-3758.

Chambers, D. P. (2003), Basin-scale thermosteric sea level variations: 1993-2002, paper presented at EGS-AGU-EUG Joint Meeting, Eur. Geophys. Soc., Nice, France.

Chambers, D. P., J. C. Ries, C. K. Shum, and B. D. Tapley (1998), On the use of tide gauges to determine altimeter drift, J. Geophys. Res., 103(C6), 12,885-12,890.

Chambers, D. P., C. A. Mehlhaff, T. J. Urban, D. Fujii, and R. S. Nerem (2002), Low-frequency variations in global mean sea level: 1950-2000, J. Geophys. Res., 107(C4), 3026, doi:10.1029/2001JC001089.

Chambers, D. P., S. A. Hayes, J. C. Ries, and T. J. Urban (2003), New TOPEX sea state bias models and their effect on global mean sea level, J. Geophys. Res., 108(C10), 3305, doi:10.1029/ 2003JC001839.

Chao, B. F. (1991), Man, water, and global sea level, Eos Trans. $A G U, 72(45), 492$.

Chao, B. F. (1995), Anthropogenic impact on global geodynamics due to reservoir water impoundment, Geophys. Res. Lett., 22(24), 3529-3532.

Chelton, D. B., J. C. Ries, B. J. Haines, L.-L. Fu, and P. S. Callahan (2001), Satellite altimetry, in Satellite Altimetry and Earth Sciences, edited by L.-L. Fu and A. Cazenave, pp. 1131, Academic, San Diego, Calif.

Chen, J. L., C. R. Wilson, D. P. Chambers, R. S. Nerem, and B. D. Tapley (1998), Seasonal global water mass budget and mean sea level variations, Geophys. Res. Lett., 25(19), 3555-3558.

Christensen, E. J., et al. (1994), Calibration of TOPEX/Poseidon at Platform Harvest, J. Geophys. Res., 99(C12), 24,465-24,486.

Church, J., J. M. Gregory, P. Huybrechts, M. Kuhn, K. Lambeck, M. T. Nhuan, D. Qin, and P. L. Woodworth (2001), Changes in sea level, in Climate Change 2001: The Scientific Basis, Contribution of Working Group I to the Third Assessment Report of the Intergovernmental Panel on Climate Change, edited by J. T. Houghton et al., pp. 639-693, Cambridge Univ. Press, New York.

Cox, C. M., and B. F. Chao (2002), Detection of a large-scale mass redistribution in the terrestrial system since 1998, Science, 297, 831-833.

Davis, C. H., C. A. Kluever, B. J. Haines, C. Perez, and Y. T. Yoon (2000), Improved elevation-change measurement of the southern Greenland Ice Sheet from satellite radar altimetry, IEEE Trans. Geosci. Remote Sens., 38(4), 1367-1378.

De Angelis, H., and P. Skvarca (2003), Glacier surge after ice shelf collapse, Science, 299, 1560-1562.

Dickey, J. O., S. L. Marcus, O. de Viron, and I. Fukumori (2002), Recent Earth oblateness variations: Unraveling climate and postglacial rebound effects, Science, 298, 1975-1977.

Dickman, S. R. (1979), Continental drift and true polar wandering, Geophys. J. R. Astron. Soc., 57, 41-50.

Dickson, R. R., H. H. Lamb, S.-A. Malmberg, and A. J. Lee (1988), The Great Salinity Anomaly in the northern North Atlantic, 1968-1982, Prog. Oceanogr., 20, 103-151.

Dirmeyer, P. A., A. J. Dolman, and N. Sato (1999), The pilot phase of the Global Soil Wetness Project, Bull. Am. Meteorol. Soc., 80(5), 851-878.

Douglas, B. C. (1991), Global sea level rise, J. Geophys. Res., 96(C4), 6981-6992.

Douglas, B. C. (1995), Global sea level change: Determination and interpretation, U.S. Natl. Rep. Int. Union Geod. Geophys. 19911994, Rev. Geophys., 33, 1425-1432.

Douglas, B. C. (2001), Sea level change in the era of the recording tide gauge, in Sea Level Rise, History and Consequences, edited by B. C. Douglas, M. S. Kearney, and S. P. Leatherman, pp. 3764, Academic, San Diego, Calif. 
Dyurgerov, M. (2002), Glacier mass balance and regime, report, 88 pp., Inst. of Arct. and Alp. Res., Univ. of Colo., Boulder.

Dyurgerov, M. B., and M. F. Meier (2000), Twentieth century climate change: Evidence from small glaciers, Proc. Natl. Acad. Sci. U. S. A., 97(4), 1406-1411.

Forte, A. M., and W. R. Peltier (1991), Viscous flow models of global geophysical observables: 1. Forward problems, J. Geophys. Res., 96(B12), 20,131-20,159.

Fu, L.-L. (2003), Wide-swath altimetric measurement of ocean surface topography, report, 67 pp., Jet Propul. Lab., Pasadena, Calif.

Gill, A. E. (1982), Atmosphere-Ocean Dynamics, 662 pp., Academic, San Diego, Calif.

Gille, S. T. (2002), Warming of the Southern Ocean since the 1950s, Science, 295, 1275-1277.

Gleick, P. H. (1992), Environmental consequences of hydroelectric development-The role of facility size and type, Energy, 17(8), $735-747$.

Gornitz, V. (2001), Impoundment, groundwater mining, and other hydrologic transformations: Impacts on global sea level rise, in Sea Level Rise, History and Consequences, edited by B. C. Douglas, M. S. Kearney, and S. P. Leatherman, pp. 97-119, Academic, San Diego, Calif.

Gornitz, V., C. Rosenzweig, and D. Hillel (1997), Effects of anthropogenic intervention in the land hydrological cycles on global sea level rise, Global Planet. Change, 14, 97-116.

Gregory, J. M., et al. (2001), Comparison of results from several AOGCMs for global and regional sea level change 1900-2100, Clim. Dyn., 18, 225-240.

Guinehut, S. (2002), Vers une utilisation combinee des donnees altimetriques et des mesures des flotteurs profilants, thèse de doctorat, Univ. de Toulouse, Toulouse, France.

Hager, B. H., and R. W. Clayton (1989), Constraints on the structure of mantle convection using seismic observations, flow models and the geoid, in Mantle Convection, Plate Tectonics and Global Geodynamics, edited by W. R. Peltier, pp. 765-816, Gordon and Breach, Newark, N. J.

Haines, B. J., and Y. E. Bar-Sever (1998), Monitoring the TOPEX microwave radiometer with GPS: Stability of columnar water vapor measurements, Geophys. Res. Lett., 25(19), 3563-3566.

Hayne, G. S., D. W. Hancock, and C. L. Purdy (1994), TOPEX altimeter range stability estimates from calibration mode data, TOPEX/POSEIDON Res. News, 3, 18-22.

Houghton, J. T., L. G. Meira Filho, B. A. Callander, N. Harris, A. Kattenberg, and K. Maskell (Eds.) (1996), Climate Change 1995: The Science of Climate Change, 572 pp., Cambridge Univ. Press, New York.

Houghton, J. T., Y. Ding, D. J. Griggs, M. Noguer, P. J. van der Linden, X. Dai, K. Maskell, and C. A. Johnson (Eds.) (2001), Climate Change 2001: The Scientific Basis, 881 pp., Cambridge Univ. Press, New York.

Huang, J., H. van den Dool, and K. P. Georgakakos (1996), Analysis of model-calculated soil moisture over the United States (1931-1993) and application to long range temperature forecasts, J. Clim., 9, 1350-1362.

Intergovernmental Oceanographic Commission (1997), Global Sea Level Observing System (GLOSS) implementation plan-1997, IOC Tech. Ser. 50, 91 pp., Paris.

Ishii, M., M. Kimoto, and M. Kachi (2003), Historical ocean subsurface temperature analysis with error estimates, Mon. Weather Rev., 131, 51-73.

Jacobs, S. S., C. F. Giulivi, and P. A. Mele (2002), Freshening of the Ross Sea during the late 20th century, Science, 297, 386389.

Jayne, S. R., J. M. Wahr, and F. O. Bryan (2003), Observing ocean heat content using satellite gravity and altimetry, J. Geophys. Res., 108(C2), 3031, doi:10.1029/2002JC001619.

Johnston, P., and K. Lambeck (1999), Postglacial rebound and sea level contributions to changes in the geoid and Earth's rotation axis, Geophys. J. Int., 136, 537-558.
Kaufmann, G., and K. Lambeck (2000), Mantle dynamics, postglacial rebound and the radial viscosity profile, Phys. Earth Planet. Inter, 121, 301-324.

Krabill, W., W. Abdalati, E. Frederick, S. Manizade, C. Martin, J. Sonntag, R. Swift, R. Thomas, W. Wright, and J. Yungel (2000), Greenland ice sheet: High-elevation balance and peripheral thinning, Science, 289, 428-430.

Lambeck, K., and P. Johnston (1998), The viscosity of the mantle: Evidence from the analysis of glacial rebound phenomena, in The Earth's Mantle, Composition, Structure and Evolution, edited by I. Jackson, pp. 461-502, Cambridge Univ. Press, New York.

Leuliette, E. W., R. S. Nerem, and G. T. Mitchum (2004), Results of TOPEX/Poseidon and Jason-1 calibration to construct a continuous record of mean sea level, Mar. Geod., in press.

Levitus, S., J. I. Antonov, T. P. Boyer, and C. Stephens (2000a), Warming of the world ocean, Science, 287, 2225-2229.

Levitus, S., C. Stephens, J. I. Antonov, and T. P. Boyer (2000b), Yearly and year-Season upper ocean temperature anomaly fields, 1948-1998, NOAA Atlas NESDIS 40, Natl. Oceanic and Atmos. Admin., Silver Spring, Md. (Available at http:// www.nodc.noaa.gov/OC5/PDF/ATLAS/nesdis40.pdf)

McCarthy, D. D., and B. Luzin (1996), Path of the mean rotational pole from 1899-1994, Geophys. J. Int., 125, 623-629.

Meier, M. F., and M. Dyurgerov (2002), How Alaska affects the world, Science, 297, 350-351.

Miller, L., and B. C. Douglas (2004), Mass and volume contributions to 20th century global sea level rise, Nature, 428, 406-409, doi:10.1038/nature02309.

Milly, P. C. D., and A. B. Shmakin (2002), Global modeling of land water and energy balances: 1 . The land dynamics (LaD) model, J. Hydrometeorol., 3, 283-299.

Milly, P. C. D., A. Cazenave, and M. C. Gennero (2003), Contribution of climate-driven change in continental water storage to recent sea-level rise, Proc. Natl. Acad. Sci. U. S. A., 100(23), $13,158-13,161$.

Minster, J.-F., C. Brossier, and P. Rogel (1995), Variation of the mean sea level from TOPEX/POSEIDON data, J. Geophys. Res., 100(C12), 25,153-25,162.

Minster, J. F., A. Cazenave, Y. V. Serafini, F. Mercier, M. C. Gennero, and P. Rogel (1999), Annual cycle in mean sea level from Topex-Poseidon and ERS-1: Inference on the global hydrological cycle, Global Planet. Change, 20, 57-66.

Mintz, Y., and Y. V. Serafini (1992), A global monthly climatology of soil-moisture and water-balance, Clim. Dyn., 8(1), 13-27.

Mitchum, G. T. (1994), Comparison of TOPEX sea surface heights and tide gauge sea levels, J. Geophys. Res., 99(C12), 24,54124,554 .

Mitchum, G. (1997), A tide gauge network for altimeter calibration, in IGS/PSMSL Sea Level Workshop, edited by R. Neilan, P. Woodworth, and P. Van Scoy, pp. 45-56, Jet Propul. Lab., Pasadena, Calif.

Mitchum, G. T. (1998), Monitoring the stability of satellite altimeters with tide gauges, J. Atmos. Oceanic Technol., 15, 721-730.

Mitchum, G. T. (2000), An improved calibration of satellite altimetric heights using tide gauge sea levels with adjustment for land motion, Mar. Geod., 23, 145-166.

Mitrovica, J. X., and A. Forte (2004), A new inference of mantle viscosity based upon joint inversion of convection and glacial isostatic adjustment data, Earth Planet. Sci. Lett., in press.

Mitrovica, J. X., and W. R. Peltier (1989), Pleistocene deglaciation and the global gravity field, J. Geophys. Res., 94(B10), 13,65113,671 .

Mitrovica, J. X., M. E. Tamisiea, J. L. Davis, and G. A. Milne (2001), Recent mass balance of polar ice sheets inferred from patterns of global sea level change, Nature, 409, 1026-1029.

Munk, W. (2002), Twentieth century sea level: An enigma, Proc. Natl. Acad. Sci. U. S. A., 99(10), 6550-6555.

Munk, W. (2003), Ocean freshening, sea level rising, Science, 300, 2041-2043. 
Nerem, R. S. (1995a), Global mean sea level variations from TOPEX/Poseidon altimeter data, Science, 268, 708-710.

Nerem, R. S. (1995b), Measuring global mean sea level variations using TOPEX/POSEIDON altimeter data, J. Geophys. Res., 100(C12), 25,135-25,152.

Nerem, R. S., and G. T. Mitchum (2001a), Observations of sea level change from satellite altimetry, in Sea Level Rise: History and Consequences, edited by B. C. Douglas, M. S. Kearney, and S. P. Leatherman, pp. 121-163, Academic, San Diego, Calif.

Nerem, R. S., and G. T. Mitchum (2001b), Sea level change, in Satellite Altimetry and Earth Sciences: A Handbook of Techniques and Applications, edited by $\mathrm{L}$. Fu and A. Cazenave, pp. 329-349, Academic, San Diego, Calif.

Nerem, R. S., and G. T. Mitchum (2002), Estimates of vertical crustal motion derived from differences of TOPEX/POSEIDON and tide gauge sea level measurements, Geophys. Res. Lett., 29(19), 1934, doi:10.1029/2002GL015037.

Nerem, R. S., B. J. Haines, J. Hendricks, J. F. Minster, G. T. Mitchum, and W. B. White (1997), Improved determination of global mean sea level variations using TOPEX/POSEIDON altimeter data, Geophys. Res. Lett., 24(11), 1331-1334.

Nerem, R. S., D. P. Chambers, E. W. Leuliette, G. T. Mitchum, and B. S. Giese (1999), Variations in global mean sea level associated with the 1997-1998 ENSO event: Implications for measuring long term sea level change, Geophys. Res. Lett., 26(19), 30053008 .

Nerem, R. S., J. Wahr, and E. W. Leuliette (2004), Measuring the distribution of ocean mass using GRACE, Space Sci. Rev., 108(1), 331-344.

Panasyasuk, S. V., and B. H. Hager (2000), Inversion for mantle viscosity profiles constrained by dynamic topography and the geoid, and their estimated errors, Geophys. J. Int., 143, 821-836.

Peltier, W. R. (1998), Postglacial variations in the level of the sea: Implications for climate dynamics and solid-Earth geophysics, Rev. Geophys., 36(4), 603-689.

Peltier, W. R. (2001), Global glacial isostatic adjustment and modern instrumental records of relative sea level history, in Sea Level Rise, History and Consequences, edited by B. C. Douglas, M. S. Kearney, and S. P. Leatherman, pp. 65-95, Academic, San Diego, Calif.

Peltier, W. R., and X. H. Jiang (1996), Glacial isostatic adjustment and Earth rotation: Refined constraints on the viscosity of the deepest mantle, J. Geophys. Res., 101(B2), 3269-3290.

Plag, H.-P., and H.-U. Juttner (2001), Inversion of global tide gauge data for present-day ice load changes, in Proceedings of the Second International Symposium on Environmental Research in the Arctic and Fifth Ny-Alesund Scientific Seminar, pp. 301318, Mem. Natl. Inst. Polar Res., Tokyo, Japan.

Richards, M. A., H. P. Bunge, Y. Ricard, and J. R. Baumgardner (1999), Polar wandering in mantle convection models, Geophys. Res. Lett., 26(12), 1777-1780.

Rignot, E., and R. Thomas (2002), Mass balance of polar ice sheets, Science, 297, 1502-1506.

Rignot, E., A. Rivera, and G. Casassa (2003), Contribution of the Patagonia icefields of South America to sea level rise, Science, 302, 434-437.

Rothrock, D. A., Y. Yu, and G. A. Maykut (1999), Thinning of the Arctic sea-ice cover, Geophys. Res. Lett., 26(23), 3469-3472.

Sabadini, R., and B. L. A. Vermeersen (2002), Long-term rotation instabilities of the Earth: A reanalysis, in Ice Sheets, Sea Level, and the Dynamic Earth, Geodyn. Ser., vol. 29, edited by J. X. Mitrovica and B. L. A. Vermeersen, pp. 51-67, AGU, Washington, D. C.

Sahagian, D. (2000), Global physical effects of anthropogenic hydrological alterations: Sea level and water redistribution, Global Planet. Change, 25, 39-48.
Serreze, M. C., J. E. Walsh, F. S. Chapin, T. Osterkamp, M. Dyurgerov, V. Romanovsky, W. C. Oechel, J. Morison, T. Zhang, and R. G. Barry (2000), Observational evidence of recent change in the northern high-latitude environment, Clim. Change, 46(1-2), 159-207.

Shiklomanov, A. I. (1997), Comprehensive assessment of the freshwater resources of the world: Assessment of water resources and water availability in the world, report, World Meteorol. Organ., Geneva, Switzerland.

Stephenson, F. R., and L. V. Morrison (1995), Long-term fluctuations in the Earth's rotation: 700 BC to AD 1990, Philos. Trans. R. Soc. London, Ser. A, 351, 169-173.

Sun, S., and J. E. Hansen (2003), Climate simulations for 19512050 with a coupled atmosphere-ocean model, J. Clim., 16, 2807-2826.

Tamisiea, M. E., J. X. Mitrovica, G. A. Milne, and J. L. Davis (2001), Global geoid and sea level changes due to present-day ice mass fluctuations, J. Geophys. Res., 106(B12), 30,84930,863 .

Tamisiea, M. E., J. X. Mitrovica, and J. L. Davis (2003), A method for detecting rapid mass flux of small glaciers using local sea level variations, Earth Planet. Sci. Lett., 213, 477-485.

Tapley, B. D., et al. (1994), Precision orbit determination for TOPEX/POSEIDON, J. Geophys. Res., 99(C12), 24,383-24,404. Thomas, R., T. Akins, B. Csatho, M. Fahnestock, P. Gogineni, C. Kim, and J. Sonntag (2000), Mass balance of the Greenland ice sheet at high elevations, Science, 289, 426-428.

Velicogna, I., and J. Wahr (2002), Postglacial rebound and Earth's viscosity structure from GRACE, J. Geophys. Res., 107(B12), 2376, doi:10.1029/2001JB001735.

Vermeersen, L. L. A., A. Fournier, and R. Sabadini (1997), Changes in rotation induced by Pleistocene ice masses with stratified analytical Earth models, J. Geophys. Res., 102(B12), 27,689-27,702.

Wahr, J., D. Wingham, and C. Bentley (2000), A method of combining ICESat and GRACE satellite data to constrain Antarctic mass balance, J. Geophys. Res., 105(B7), 16,27916,294 .

White, W. B., D. R. Cayan, M. D. Dettinger, and G. Auad (2001), Sources of global warming in upper ocean temperature during El Niño, J. Geophys. Res., 106(C3), 4349-4367.

Willis, J. K., D. Roemmich, and B. Cornuelle (2003), Combining altimetric height with broadscale profile data to estimate steric height, heat storage, subsurface temperature, and sea-surface temperature variability, J. Geophys. Res., 108(C9), 3292, doi:10.1029/2002JC001755.

Willmott, C. J., C. M. Rowe, and Y. Mintz (1985), Climatology of the terrestrial seasonal water cycle, J. Clim., 5, 589-606.

Woodworth, P. L., and R. Player (2003), The Permanent Service for Mean Sea Level: An update to the 21st century, J. Coastal Res., 19, 287-295.

Woodworth, P. L., J. M. Gregory, and R. J. Nicholls (2004), Long term sea level changes and their impacts, in The Sea, edited by A. Robinson and K. Brink, Harvard Univ. Press, Cambridge, Mass., in press.

Zwally, H. J., W. Abdalati, T. Herring, K. Larson, J. Saba, and K. Steffen (2002), Surface melt-induced acceleration of Greenland ice-sheet flow, Science, 297, 218-222.

A. Cazenave, Laboratoire d'Etudes en Géophysique et Océanographie Spatiales, GRGS, CNES, 18 Avenue E. Belin, 31401 Toulouse Cedex 04, France. (anny.cazenave@cnes.fr)

R. S. Nerem, Colorado Center for Astrodynamics Research, University of Colorado, UCB 431, Boulder, CO 80309-0431, USA. (nerem@ colorado. edu) 